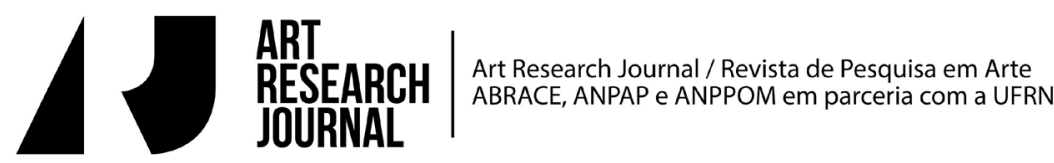

\section{Escutar caminhos}

Leandra Lambert

leandra.lambert@gmail.com

\section{Introdução: caminhar labirintos, met-hodologia sônica, atlanticaos}

Um labirinto se constrói com muitos caminhos. Um dos movimentos fundamentais em minha prática artística é o caminhar. Andar sobre os próprios pés é o modo de locomoção primordial da nossa espécie. Em um planeta que é consumido na acelerada queima de combustíveis fósseis, caminhar é ato de resistência, é desvio e diáspora, movimento terreno, na escala sublunar, do tamanho dos nossos próprios passos, no tempo vago dos nossos próprios passos. Nessas caminhadas deixo-me guiar pelos sons ambientes, um exercício que me provoca a entrada em um estado de deriva sensorial, cognitiva e imaginativa. Esta ação de escutar em profundidade é outro movimento fundamental. Na junção desses dois movimentos, a relação do corpo com o meio é sentida como alterada e intensificada. Caminhar em estado de escuta profunda resulta em não mais estar no ambiente, mas em ser ambiente. O caminhar torna-se um vagar: não há ponto de chegada, trajeto certo. Experimento camadas de espaço-tempo que se superpõem e se contaminam, sentidos que se misturam.

Ao exercer a errância, qualquer lugar pode se tornar labirinto. Um labirinto que não fecha: abre-se em redes que se expandem e geram outras redes labirínticas. Neste processo surge um terceiro gesto fundamental: fabular. Traçar um caminho é também traçar um desenho, uma narrativa e uma cartografia. Escutar é também a possibilidade de construir sentidos a partir do escutado, contar o que se ouviu, é a potencialidade de um dizer. Para se falar do gesto de fabular, começo já a fabular. A experiência e a ficção andam juntas. A partir dos gestos se configuram os labirintos e o método de escrever, fio que se estende em teia e em nós, encruzilhadas; os nós dos problemas insolúveis, mas que ainda assim necessitam enfrentamento; os nós na corda que guia o caminho por um labirinto ou floresta; os nós que amarram 
as velas de um barco no oceano, que o permitem aportar em algumas costas, para que não se perca para sempre em derivas.

Este artigo constitui-se a partir de trechos da tese de Doutorado em Artes defendida no PPGArtes-UERJ, intitulada "Caminhos Atlânticos, Cartas de Terras Insondáveis: vagar, escutar, fabular". Os nós da tese são definidos a partir dos elementos do próprio título: o ato de fazer caminhos, o que é ser atlântico em algumas de suas múltiplas dimensões, as cartas em seu triplo sentido de missivas, de mapas e de jogo, as terras insondáveis como o território do que nunca se dá a conhecer totalmente, repleto de ausências, rastros, vestígios e fantasmagorias. Partindo desses nós, o labirinto se desenrola: o fio de Ariadne faz achar o caminho, e é o próprio labirinto que se expande. Expandido, toca o que nos abrange a todos como espécie, como cultura e como seres vivos, nossa casa comum, nosso lugar de ser, estar e viver: a Terra, a combalida Gaia que não permite mais que ignoremos as violências a que vem sendo submetida. A Terra é também dos mares e profundezas: posso nomeá-la como Terraoceana, em mais um ato de fabulação.

Minha pesquisa-processo em artes surgiu e se expandiu principalmente a partir de experiências com a série Atlântica, que se configura como um atlas interminável e articula práticas artísticas em três espaços, três escalas: a Avenida Atlântica, em Copacabana, no Rio de Janeiro; a Mata Atlântica, ecossistema ameaçado que se situa em áreas próximas do litoral brasileiro subequatorial; e o Oceano Atlântico, com sua história vinculada à colonização e seu intenso trânsito atual - aéreo, marítimo, de capital, de informação. Atlântica acordou entre o mar e os motores, seguiu por rios e matas e vem se desdobrando e proliferando em diversas (sub) séries. Nesses deslocamentos atlânticos há também uma atenção às relações do corpo com os meios pelos quais o trajeto se dá; rua, floresta, barco, flutuação, mergulho, naufrágio: quando os pés levam o corpo em um duro espaço geometricamente (des)ordenado, quando estão no chão vivo das matas, quando se equilibram no precário e vulnerável de uma embarcação, quando experimentam a leveza nas águas, quando não há mais chão.

Deste processo surgiram outras séries de trabalhos, como as Cartas de Terras Insondáveis. A partir daí se desenvolveu uma "met-hodologia sônica" que também poderia ser chamada de "met-hodologia atlanticaótica", que passou a ser aplicada a outros ambientes, considerando sempre a história e as peculiaridades de cada 
lugar. Com a realização de gravações de campo, anotações e fotografias, tal prática posteriormente se condensa em mídias diversas, em composições sonoras, visuais, textuais.

Os conceitos de hodologia e de espaço hodológico, presentes em proposições do psicólogo Kurt Lewin e de filósofos como Kant, Heidegger, Sartre, Deleuze e Michel de Certeau, vêm sendo utilizados por Gilles Tiberghien (2012) no estudo de certos aspectos da arte contemporânea. A hodologia trata da construção pessoal de caminhos ou caminhadas. O termo deriva do grego hodos, que significa rota, viagem ou caminho (Jackson apud Tiberghien, 2012). John Brinckeroff Jackson observa que a raiz hodos também é encontrada em methodos: "um modo (way) de ação regular e sistemática" (apud Tiberghien, 2012, p. 163). No caso da minha prática hodológica específica, o método abre-se ao acaso, às interferências e irregularidades, o sistema escapa de regras estritas, e a disciplina busca, conforme já propunha Rimbaud no séc. XIX, em sua "carta do vidente", o "desregramento de todos os sentidos".

Um método hodológico é coerente com esta proposta aberta, em processo. Tiberghien observa a oposição dialética entre dois tipos de vias: as rotas prontas, ruas, estradas e superfícies construídas para facilitar e acelerar acessos, passagens que dizem respeito ao hábito; e os caminhos praticados e inventados a cada vez, processuais, que exigem tempo, que implicam mesmo "perder tempo", que esbarram nos perigos da errância, do vagar (2012, p. 163-165). A hodologia, segundo essa perspectiva, privilegia o segundo tipo, o caminho que se faz no ato; "o espaço hodológico é algo que se relaciona com a ação" (Uexküll apud Tiberghien, 2012, p. 169). É possível viajar em qualquer lugar e usar a desorientação e a errância como met-hodologia. Bill Viola (1988) aplicou essa prática a seu vídeo Hatsu Yume, quando esteve no Japão, em um país em que se sentia perdido. Não basta andar por uma via, seguir uma estrada: é necessário o desvio, o incerto, o vagar; é preciso caminhar o impreciso, é preciso se perder. Yoko Ono, em uma de suas instruções, resumia: "Faça um mapa para se perder".

Segundo Tiberghien, o espaço hodológico e a deriva situacionista guardam essa relação:

O espaço que percorre um caminhante é um espaço atravessado por afetos [...]. É também o espaço psicogeográfico da deriva teorizado por Guy Debord. [...] A deriva é apresentada como o meio para a 
psicogeografia: um modo ao mesmo tempo metódico e aleatório de descobrir uma face inédita das cidades assim exploradas. [...]

A deriva [...] é então sensorial e afetiva e requer, segundo a expressão de Debord, "a afirmação de um comportamento lúdico-construtivo". Ela se realiza sobre um "terreno passional-objetivo"... (Tiberghien, 2012, p. 170).

Em minha met-hodologia, vago em um estado de crescente desregramento dos sentidos, seguindo sons e conversas, mensagens fragmentadas escritas pelas paredes, rastros e asperezas deixados nas superfícies. Vagar em escuta, em abertura poética às sutilezas e violências de cada ambiente, percebendo a voz como corpo que se distende no espaço, buscando o território que escapa e resiste às colonizações, o hemisfério que se opõe à consciência clara e desvela sombras sempre incompletas, fantasmas, assombros, o indizível que ainda assim precisa ser dito. Essa tarefa de dizer e narrar não pode, no entanto, se equivocar na armadilha da identificação: não sabemos de fato o que é ser o outro, o seu sofrimento; o lugar do outro é terra incógnita irredutível. Só podemos sondá-la, a uma certa distância. Existe, entretanto, uma ligação, uma comunalidade, sempre a possibilidade do reconhecimento, de um co-sentir, do testemunho, de uma responsabilidade. Essa ligação se dá no presente, mas se constrói com os co-habitantes do nosso tempo, do passado e do porvir. Pode-se perguntar: "quem se importa?", e cabe-nos responder, sempre, que nós nos importamos. É assim que "o ouvinte que fica até o final ${ }^{\prime 1}$ encontra meios de passar adiante o que ouviu, de fazer palavra, gesto e imagem do que escutou; é assim que se pode escutar caminhos e possibilidades.

\section{Escutar além das ondas, restos e rastros catados pelos caminhos}

Em meus trabalhos a escuta é constitutiva dos processos e questionamentos desde o princípio; o exercício da escuta gera trabalhos. O que não significa que a escu-

1 Referência ao sonho narrado por Primo Levi, em que o autor tenta contar os horrores do holocausto, mas encontra dificuldades em dizer e ser ouvido. Este sonho é analisado por Jeanne Marie Gagnebin e auxilia a pensar a escuta e a testemunha: "Testemunha seria também aquele que não vai embora, que consegue ouvir a narração insuportável do outro e que aceita que suas palavras levem adiante, como num revezamento, a história do outro: não por culpabilidade ou compaixão, mas porque somente a transmissão simbólica, assumida apesar e por causa do sofrimento indizível, somente essa retomada reflexiva do passado pode nos ajudar a não repeti-lo infinitamente, mas a ousar esboçar uma outra história, a inventar o presente" (Gagnebin, 2009, p. 57, grifos meus). 
ta e o trabalho não possam também levar a tatear, provar, cheirar, ver, mover, rememorar. Assim, a abordagem que parte das Atlânticas, das Cartas de Terras Insondáveis e de outras séries e projetos que vão surgindo, como Cut-up Tragedy, precisa incluir algumas questões referentes a auralidade e percepção, territórios e itinerários sonoros, memória auditiva e imaginação sônica. A imaginação é especialmente requerida diante do insondável: insondável é o que não se sonda - profundezas de acesso impossível. A origem etimológica de sondar se refere a ir para debaixo da onda (do latim subundare; unda, onda, também presente em inundar) e a verificar a profundidade das águas, mas através de um instrumento, uma referência, não diretamente, mas através de sinais, marcas.

Além das profundezas aquáticas sondáveis ou insondáveis, o som mesmo é feito de ondas, constitui-se de e move-se em ondas. Ondas, sejam sonoras ou do mar, são definidas pela física como perturbações que se propagam em algum meio, no espaço e no tempo. Estamos sempre sob essas perturbações, sob algumas ondas sonoras, inundados - e incapazes de medir a profundidade a que estamos mergulhados, de calcular todas as derivações, memórias e imagens que essas ondas geram. O acesso aqui é sempre incompleto, entrevisto e entreouvido: em limiar.

A escuta em abismo se dá no limiar do insondável: como o efeito de espelhos "em abismo", a escuta se desdobra em incontáveis imagens, tempos, lugares, virtualidades, tendendo ao infinito. São dobras e mais dobras, ondas, reverberações e ressonâncias. As dobras das orelhas, os ouvidos em concha e a profundidade dos canais auditivos, os labirintos em nossos corpos, são aptos a essa recepção que é também ato, construção, elaboração e criação muito além dos ouvidos: a imaginação e a memória auditiva, a relação entre audição e rastros, vestígios e mesmo "fantasmas" ou alucinações sonoras. O som se propaga em ondas, mas também além delas; penetra meandros, mas também os constrói.

Ouvir rastros, ao invés de vê-los: por que ouvir ao invés de ver, por que não tatear rastros, tentar prová-los ou ser guiada pelo olfato, como tantos bichos? A escuta relaciona-se ao que ainda não se vê, ao que está a distância ou escondido, ao que talvez se aproxime e se faça ver - talvez. A escuta pode cair no vazio e no mistério mudo sem respostas, mas também realiza imagens e ficções, gera imagens e ficções rapidamente mutáveis no tempo, desde as mais prosaicas inquirições: "Que é que faz esse som, é coisa, homem, mulher ou bicho?", e cada possível coi- 
sa - homem, mulher ou bicho - já desencadeia uma série de imagens virtuais e inícios de histórias, fragmentos de ficções; a escuta é imaginante. O som tem algo de Proteus: se transforma, não se deixa apreender e gera imagens e formas. Sereias, iaras, ninfas, loreleis e elfos das águas: seduzem com suas vozes, seu canto arrasta para o fundo, para o desconhecido.

Em Sinister Resonances, o músico, compositor e pesquisador David Toop investiga a natureza fantasmática do som e sua relação com rastros e memórias, assim como com estados alucinatórios. Começa relatando uma experiência e as reflexões que esta desperta:

Fui acordado de um sono profundo e sem sonhos por uma ressonância oca, um brusco impacto de madeira sobre madeira. Havia sido um evento auditivo isolado na minha consciência - um momento de sonho sem narrativa ou duração - ou era um som real do mundo físico? O tempo de reverberação era muito longo para que o som tivesse sido gerado dentro do quarto. Isso implicava em um som vindo de outra parte da casa, um espaço ecoante, misterioso e distante. Neste caso, eu só poderia presumir a presença de um invasor, ainda que fosse uma possibilidade remota. O som veio de lugar nenhum, não pertencia a lugar algum, portanto não tinha lugar no mundo, a não ser através da minha descrição.

Palavras ao vento, vale o escrito: som é ausência, é algo encantatório, fora de vista, fora de alcance. O que fez o som? Quem está aí? O som é um vazio, é medo e assombro. Ao escutar como se ouvisse os mortos, lidando apenas com o que já se perdeu, o ouvido se afina para sintonizar sinais distantes, esbarrando no murmúrio de fantasmas. Incapaz de escrever uma história consistente, o ouvinte cede ao deslizar do tempo. [...] O som é uma ausência presente; o silêncio é uma presença ausente. Ou talvez o contrário soe melhor: o som é uma presença ausente e o silêncio uma ausência presente? Nesse sentido, o som é uma estranha e inquietante ressonância. (Toop, Loc 28-39).

Nesta dinâmica de existência e desaparecimento, de presença ausente e ausência presente, pode-se identificar o som como tendo a característica de um rastro, de um vestígio fugidio, uma matéria que foge, uma realidade que escapa - que pode chegar a sugerir a possibilidade de uma alucinação ou de um fantasma. O termo usado por David Toop, ressonância, vem do latim resonare, "soar de novo", o que já pode estabelecer uma analogia com a memória. A palavra possui um uso mais coloquial, que alude a um som cheio, profundo e reverberante; e é também um termo científico, da física ondulatória e da música. A ressonância é um dos efeitos elementares do som e só ocorre em uma relação: existem frequências em que os elementos sólidos vibram; ao serem excitados nessas frequências por algum estí- 
mulo externo, alguma fonte de energia, a matéria vibra em amplitude crescente, "respondendo" a esse estímulo, em um ciclo de amplificação. A descrição chega a ser algo erótica, como um orgasmo da matéria excitada por uma energia intensa. O efeito age à distância, pelas ondas, e é poderoso: é um "soar de novo" e soar com o outro e no outro, um soar mais alto e mais forte. Quando dizemos que estamos "afinados na mesma frequência" que alguém, talvez realmente estejamos. O efeito é também o princípio da construção dos instrumentos musicais acústicos, que possuem caixas de ressonância; e é um dos princípios do canto, em que a boca constitui uma das caixas de ressonância; e é um dos princípios do canto, em que a boca constitui uma das caixas de ressonância. O nosso corpo como um todo está sujeito a diversos fenômenos de ressonância, especialmente nas frequências graves; pode ser estimulado por isso, ou adoecer gravemente. Os nossos ouvidos também estão sujeitos a complexos sistemas de ressonância.

Ouvir um som in crescendo pode criar a imagem de uma subida, um grave ressoa nos baixios, uma frequência alta pode fazer com que se erga a cabeça, olhando para o alto, um som uniforme parece deslizar, um timbre granulado é uma textura e quase faz cócegas: a imagem carregada pelo som é sentida no corpo, ressoa na carne e nos ossos. O efeito Chladni faz ver o som: usando-se poeiras muito finas sobre superfícies que ressoam, vemos as imagens das vibrações sonoras, ondas, labirintos e mandalas que logo se transformam. O som, como fenômeno físico e psíquico, afeta todos os seres, mesmo os que não possuem audição - pois é também tátil, faz vibrar peles, superfícies e profundidades, gera calor. Propaga-se pelo ar, pela água e pelos corpos de diferentes maneiras. Pode ser usado como arma. Pode acalmar as feras, como Orfeu sabia. Pode dizer o amor, sublevar revoltas ou inflamar ódios.

A escuta pode ser ainda de sons que percebemos como organizados ou indistintos, ruídos; pode ser de vozes inarticuladas ou de uma fala; a fala cria a palavra, a palavra gera uma escrita e da escrita emergem listas, cartas, livros e enciclopédias, seja esse o trabalho de alguns minutos ou de séculos. Em todo texto escrito habitam vozes e incontáveis sonoridades, em toda imagem há a sugestão de um ambiente acústico, na matéria há o possível impacto, a virtualidade de ser tocada como um instrumento, uma frequência esperando para ser despertada pela ressonância. Os silêncios podem ser quebrados sem que haja nenhum estímulo, 
nenhuma perturbação externa, sem que onda sonora alguma seja emitida no espaço e no tempo: som lembrado, som imaginado, o pensamento que se dá como uma voz interior, a música que "não sai da cabeça", o som no sonho, a alucinação sonora, "ouvir vozes".

Todas essas questões vêm me acompanhando e se desenvolvendo desde que, entre 2009 e 2010, me distanciei do meio musical propriamente dito, encerrando atividades com projetos e bandas, para trabalhar os sons de outras formas, mais experimentais, soando no espaço-tempo ou apenas mentalmente, na imaginação-memória de cada um. Meus primeiros trabalhos como artista além da música e da performance em seus sentidos mais estritos foram feitos nesse contexto: o som sugerido em uma situação aparentemente "silenciosa", o som lembrado e imaginado a partir de perguntas, instruções, histórias. Este foi um dos eixos em minha dissertação de mestrado, "Ouvir na Pele o Terceiro Som". Seth Kim-Cohen (2010) argumenta que alguns elementos de arte sônica não dependem da audição física: trata-se de uma arte sonora conceitual, que depende de uma escuta atenta em seu sentido mais amplo e intersensorial. Assim como se estabeleceu a noção de "arte não retiniana" a partir de Duchamp, também se pode pensar em uma "arte sônica não coclear".2

Paralelamente a esses processos, minha relação com a música se transformou. O álbum Antes da Terra Incógnita compila alguns desses momentos, entre 2009 e 2012, em parcerias com Alex Mandarino. Em 2013 surgiu nosso duo, Terra Incognita, atualmente em gravação. Em Antes da Terra Incógnita, as composições surgem da relação com elementos além da música, tais como a edição e a organização de vestígios sonoros de performances e o uso de escritas e imagens como geradoras de som, interpretadas como frequências audíveis. É um território que se mistura ao da arte sonora e multimídia, podendo também tomar a forma de instalações e proposições que não são estritamente musicais, mas compostas de elementos visuais, textuais, objetos etc.

O álbum abre com a música "Cortina de Ruínas" e segue com duas séries de três composições: uma em homenagem a Ada Lovelace e outra baseada em textos ficcionais de Mandarino que descrevem três torres oníricas. A "Cortina de Ruínas"

2 A cóclea (ou caracol, devido à sua forma) é a parte auditiva do ouvido interno. É uma cavidade em forma de espiral no labirinto ósseo. Um componente central da cóclea é o órgão de Corti, o órgão sensorial da audição. 
foi construída a partir da edição de elementos sonoros de performances realizadas em uma instalação site-especific temporária que realizei, Cortina de Ruínas Leves, no Parque das Ruínas (Rio de Janeiro, 2010-2011). A cortina se localizava em um grande portal e era feita de achados e perdidos, lembranças de pequenos abandonos que soavam de diferentes formas em contato com o corpo, o vento, a chuva. Durante as performances, toquei a cortina como um instrumento, agregando também voz improvisada, processamento ao vivo e amplificação. ${ }^{3}$ As três peças sonoras que homenageiam Ada Lovelace fazem parte do trabalho ADA jpg > ADA wav, em que imagens de Ada e elementos relacionados ao seu universo (máquina de Babbage, trechos de programação em linguagem Ada, retrato de sua mãe, cartas e diagramas) são convertidos em sons através de um software específico. Foram utilizados na construção das músicas somente os arquivos de áudio resultantes desta conversão. Imagens ligadas à primeira programadora da história se transformam, através de algoritmos, em paisagens sonoras abstratas. Óleos sobre tela viram ondas de frequência; equações matemáticas geram sons robóticos que estranhamente lembram a fala humana; retratos de família se transmutam em figuras rítmicas. ${ }^{4}$

O álbum encerra com a série de músicas mais antigas, de 2009. "As Três Torres" surgiram do desejo de Mandarino de inter-relacionar ficção literária, música e criação de ambientes imaginários. Três textos curtos de Mandarino descrevem a visita a essas torres fantásticas, criando uma cadência para cada espaço. Improvisei sintetizadores e vocais buscando gerar esses ambientes e contar essas histórias de forma não verbal. Mandarino editou, sequenciou e agregou elementos, finalizando as composições. Em situação de exposição, três livros de acrílico dispostos na parede apresentam as músicas e os textos. ${ }^{5}$

3 A música recebeu o primeiro lugar no III Concurso Latino-Americano de Composição Eletro-Acústica Gustavo Becerra-Schmidt em 2012, no Chile, na categoria experimental. Teve sua estreia em 2013 no Festival Ai-Maako (Valparaíso, Chile), foi executada em concerto no Evans Hall (New London, EU, 2014) e lançada em 2015 em álbum com os vencedores de 2012 e 2013 do concurso, pelo Pueblo Nuevo Netlabel. Em 2017 foi selecionada para a programação brasileira de rádio da Documenta de Kassel, sob curadoria local de Janete El Haouli e José Augusto Mannis.

4 As peças fizeram parte da exposição virtual BR.ADA: Celebrando Ada, que foi organizada pelo site blanktape.com.br em parceria com o coletivo BR.Ada, como uma homenagem a Ada Lovelace e com o objetivo de compartilhar textos e obras com foco na importância da mulher na produção artística e/ou tecnológica. A peça Analytical Engine também entrou no álbum virtual América Latina, entre Ruídos y Ruínas (Dissonance from Hell).

5 O trabalho foi apresentado desta forma no Hap 01 (Parque Lage, RJ, 2009) e na Ocupação Arte Sonora (CC Oduvaldo Vianna Filho, RJ, 2015). 
Entre 2015 e 2016, mais três projetos musicais surgiram, dois solos e um duo: Cut-up Tragedy, que também se constitui como um trabalho textual e visual e será abordado ao fim deste texto; Strana Lektiri, com Isabel Nogueira; e Lori, o projeto solo mais recente. No Strana Lektiri ("leitura de página", em grego), todo o trabaIho é baseado em nossas vozes e em textos de mulheres, explorando os limiares de inteligibilidade através de efeitos e camadas superpostas, além de fragmentos de cantos e sons inarticulados, corporais e viscerais.

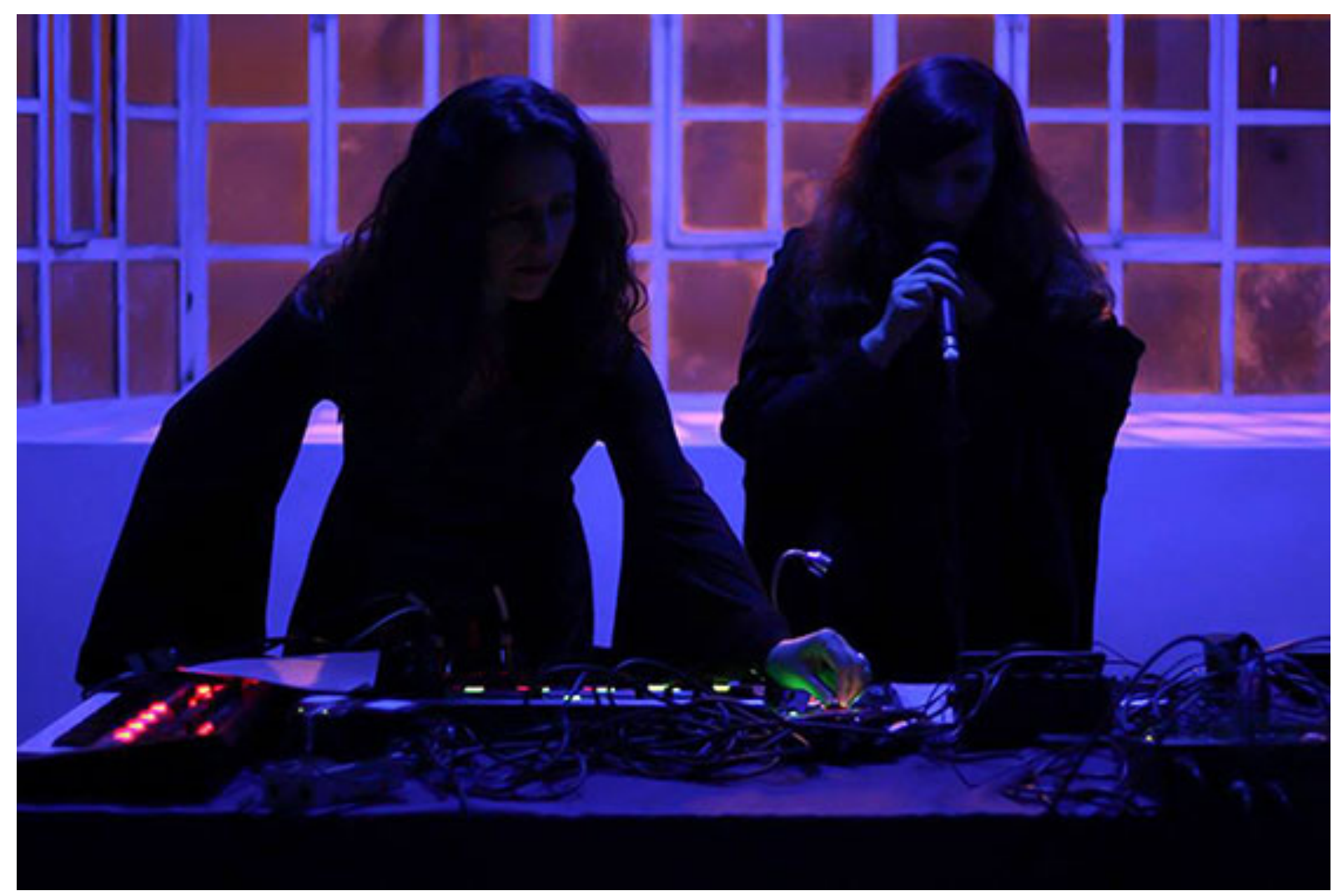

Figura 1. Strana Lektiri em apresentação no projeto Dissonantes, Ibrasotope, São Paulo, 2016. Foto de Luciene Lamano.

Em Lori, que também é um alterego, trabalho as ideias de som fantasmático, som rastro, ausência-presença, sonoridades que podem produzir assombros. Lori é feito de improvisos e experimentos com a voz, canções em ruínas, fragmentos de linguagens, glossolalias laicas-pagãs e alguns ruídos. As composições se iniciam com o canto livre, sem preocupação com a linguagem. O resultado às vezes lembra línguas conhecidas e pode gerar letras posteriores, surgidas da sonoridade. Outras camadas se somam: gravações de campo, drones, efeitos e vozes atuando como instrumentos e ambiências. Em todos esses trabalhos existe sempre a intenção de criar um espaço-tempo, uma ambiência específica, um caminho. 
Na relação entre escuta e lugar há que se destacar ainda a ideia de movimento, itinerário: mesmo que se esteja parado, o som atinge, afeta o corpo e pode gerar imagens e ficções. Isso tudo é também um lugar, e um lugar em movimento. No caso de uma caminhada sonora, no caso de uma met-hodologia sônica ${ }^{6}$, esses espaços somam-se, interagem, intertransformam-se. Cria-se um palimpsesto sônico-plástico: toda caminhada sonora é uma complexa cartografia de frequências, tempos, movimentos, espaços, contatos, sentidos. Brandon LaBelle considera que os territórios acústicos não são exatamente lugares, mas itinerários: "O som cria uma geografia relacional que é predominantemente emocional, controversa e fluida, que estimula uma forma de conhecimento que se move dentro e fora do corpo" (LaBelle, 2010b).

Ao contrário de um certo senso comum que considera o ato de escutar "passivo", ouvir tem uma força ativa: "Ao ouvir, entra-se em sinergia com o mundo e os sentidos, uma escuta/toque que é a essência do que se chama de reação visceral - uma resposta que é ao mesmo tempo fisiológica e psicológica, corpo e mente" (Dyson, 2009, p. 4). A percepção concentrada no som faz com que todos os outros sentidos se tornem mais porosos, desfocados, misturados e abertos a multiplicidades do espaço externo e à presença dos outros, com suas vozes e ruídos. A visão é um sentido que torna tudo mais objetivo, separa em "eu e você", em "sujeito e objeto", linha reta. Quando a audição comanda, não há tanto comando direto nem divisão entre interior e exterior - há um "lado de fora" que se mistura ao "dentro", que atinge, convida, aproxima - e também gera afastamentos, linhas de fuga e distâncias, poéticas do desvio; círculos, ondas, espaçamentos: "O que é meu é primeiramente minha distância, não possuo senão distâncias" (Deleuze; Guattari, 1997a, p. 127).

A visualidade não funciona de forma isolada em nenhuma situação da vida, estamos sempre imersos nas misturas, como analisa Brian Massumi (2002). Pode-se dizer o mesmo da audição ou de qualquer outro sentido. Nem mesmo nos sonhos a visualidade atua sozinha: o corpo permanece atento a outras sensações e interfere nas imagens visuais dos sonhos com esses resíduos, cria visualidade a partir de informação não visual. Há quem sonhe com todos os sentidos presentes: cheiros,

6 Para mais sobre a met-hodologia sônica, ver também artigo da própria autora, "'Experienced Sonic Fictions", publicado na revista Interference: A Journal of Audio Culture, em 2014 
texturas, sabores e sonoridades são experimentados com a mesma intensidade. Assim, não há um "campo de visão pura": a experiência visual é sempre intermodal, intersensorial. A visão "[...] sempre alimenta outros sentidos - e deles se alimenta" (Massumi, 2002, p. 154). Não existem, na verdade, sentidos naturalmente "ativos e dominantes" ou "passivos e dominados": tais percepções são construídas culturalmente e podem ser descondicionadas em práticas como o exercício da escuta atenta, em profundidade, em abismo. Audição e olfato frequentemente trazem de volta imagens vivas do passado, ainda que não sejam imagens visuais. Existem imagens em que o visual se desvaneceu e são outros sentidos que formam imagens.

Valorizar e exercer os atos de caminhar, de vagar e de escutar têm implicações éticas e estéticas específicas, que permitem diversos desdobramentos. Gilles Tiberghien ressalta que "a abordagem artística é muito importante na maneira de perceber o mundo a partir das vias que o atravessam, na medida em que ela acentua a dimensão da experiência sensível e afetiva da caminhada" (Tiberghien, 2012, p. 164).

Assim, a arte, a escuta atenta e as caminhadas e práticas intersensoriais adquirem o valor de possíveis ativadoras, geradoras e transformadoras de sensibilidades, capacidades e formas compartilhadas socialmente. No entanto, isso não é nada garantido e não se dá em um tempo plano e superficial, em um presente contínuo e luminoso. Tais possibilidades se realizam em um outro tipo de tempo: tempo-turbilhão, tempo-abismo, tempo de dobras e rastros.

O gesto de vagar, o gesto de se deslocar pela horizontalidade incerta das caminhadas sem objetivo, o gesto de se abaixar para catar coisas pelos caminhos: são gestos que, ao serem exercidos, desconstroem o utilitarismo, a automação dos gestos pré-moldados que servem a um objetivo específico, produtivista ou atlético.

Neste contexto surge também a figura do catador caminhante, do sucateiro ou trapeiro de Baudelaire e Benjamin. Os rastros, entregues ao esquecimento e aos esconderijos, se aproximam de restos a serem recolhidos pelo catador, que coleciona o que foi abandonado pelo caminho, entregue aos acasos de sua errância. Baudelaire descreve, nos Paraísos Artificiais: "Eis um homem encarregado de apanhar os restos de um dia da capital. Tudo o que a grande cidade rejeitou, tudo o que perdeu, tudo o que desdenhou, tudo o que partiu, ele o cataloga e coleciona" 
(Baudelaire, 1995, p. 354). Tal catação de rastros e restos, segundo Benjamin, é também uma característica do autêntico poeta e artista, do historiador e narrador:

Trapeiro e poeta - os dejetos dizem respeito a ambos; solitários, ambos realizam seu negócio nas horas em que os burgueses se entregam ao sono; o próprio gesto é o mesmo em ambos. Nadar fala do pas saccadé de Baudelaire; é o passo do poeta que erra pela cidade procurando a presa das rimas; deve ser também o passo do trapeiro que, a todo instante, se detém no caminho para recolher o lixo em que tropeça. (Benjamin, Paris do Segundo Império, p. 79).

Este passo incerto, irregular, é o passo do vagar. "Catar" talvez possa descrever de forma poética, com sua própria indefinição vaga e transitiva, outros verbos e operações: pode-se dizer que, nesse processo de vagar, escutar é catar sons, fabular é catar histórias e, imaginar, catar imagens; rememorar talvez seja catar rastros. 0 acaso faz "tropeçar" nas coisas, nas situações, impressões e acontecimentos; mas é preciso estar com atenção, esse tipo peculiar de atenção em fluxo. Pode se tratar também de catar coisas mais concretas, em que de fato se tropeça - como as pedras portuguesas dos meus trabalhos A Rua por Dentro e Um Fardo de Palavras.

A Rua por Dentro surge de fotografias "cegas" tiradas com uma Lomo lente olho-de-peixe, no nível do chão, em espaços em que falta uma pedra do calçamento; e de pedras portuguesas soltas coletadas na Avenida Atlântica.

As fotos são transformadas em desenhos, em crescentes graus de diferenciação. No ato de desenhar refaço, de outra forma, um percurso. Percebo outros aspectos e poéticas da imagem que fotografei e, no caminho, traço ficções, fragmentos escritos nos desenhos, nas pedras. Começo com uma fotografia e seu punctum; a seguir, realizo um desenho a partir desta foto. Depois, completo um tríptico que une os dois trabalhos anteriores, a foto e o desenho da foto, a uma das pedras coletadas e modificada com inscrições. Outras pedras e objetos escritos são devolvidos à Avenida: há uma parte do trabalho que retorna à rua e ali permanece, sem dono, talvez invisível. Este processo de "devolução" eventualmente é registrado e gera novas fotografias, novos desenhos e textos, em sucessivos desdobramentos, em ciclos de realimentação. Os textos que compõem esses desenhos se referem, em geral, a quedas e ausências, a situações duras e de perdas. Um Fardo de Palavras constitui-se como uma coleção de mais de cem pedras portuguesas catadas, carregadas pelas ruas e escritas, formando, no chão, um poema à deriva. Um outro trabalho que surge com essas pedras catadas é o Deslocamento de Pedras 
Atlânticas: pedras portuguesas encontradas na Avenida Atlântica são escritas com frases-poemas e colocadas em meio a pedras nas vias rurais, nas trilhas e nos rios em regiões de Mata Atlântica; pedras e cascalhos comuns nessa região passam pelo mesmo processo e são colocadas na Avenida, na praia, no mar. Vagar, escutar e catar, em meus processos, são atividades poéticas - que compõem o fabular.

Figura 2. Detalhe de A Rua Por Dentro - Guardo o que não tem Valor. 2013.

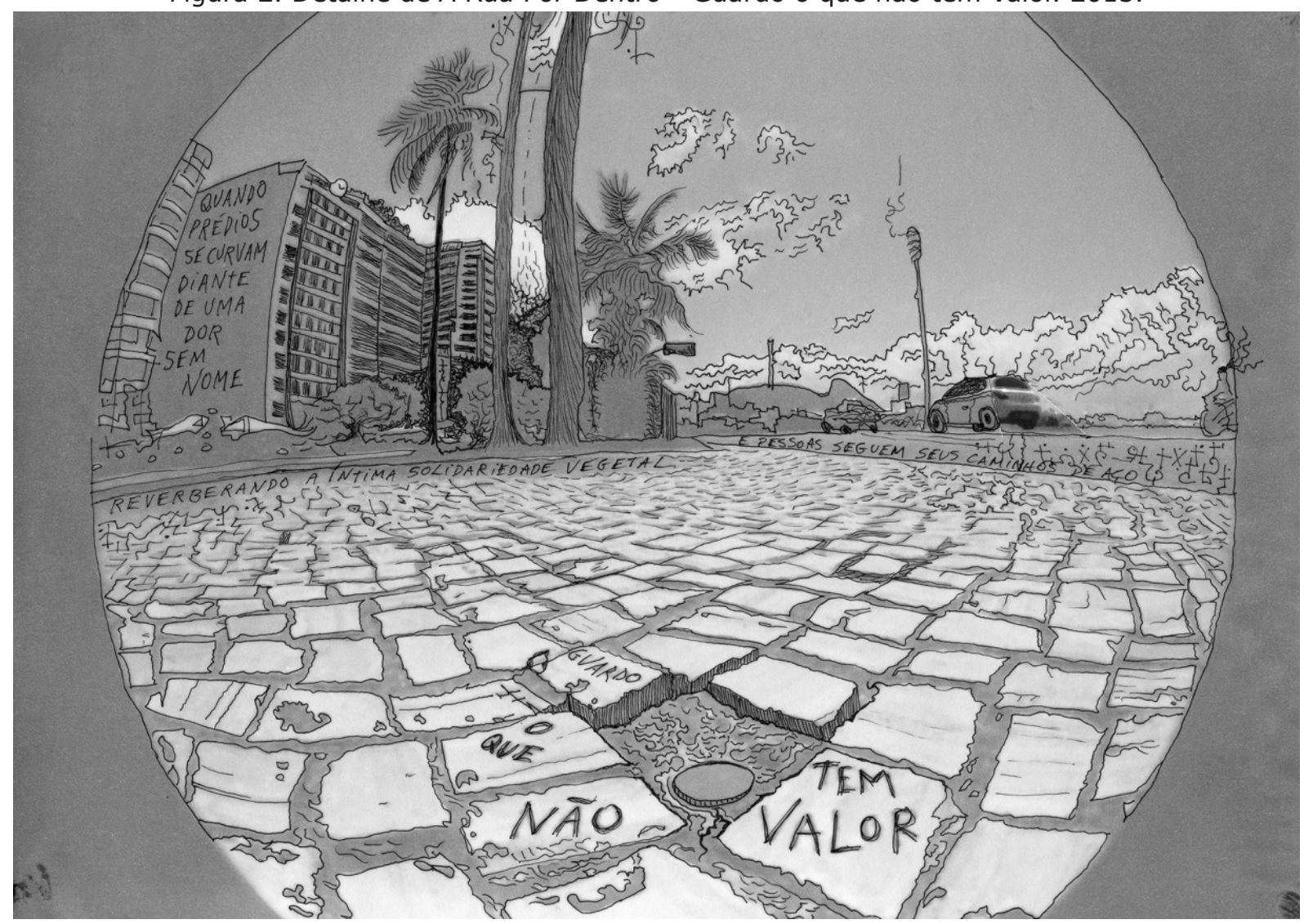




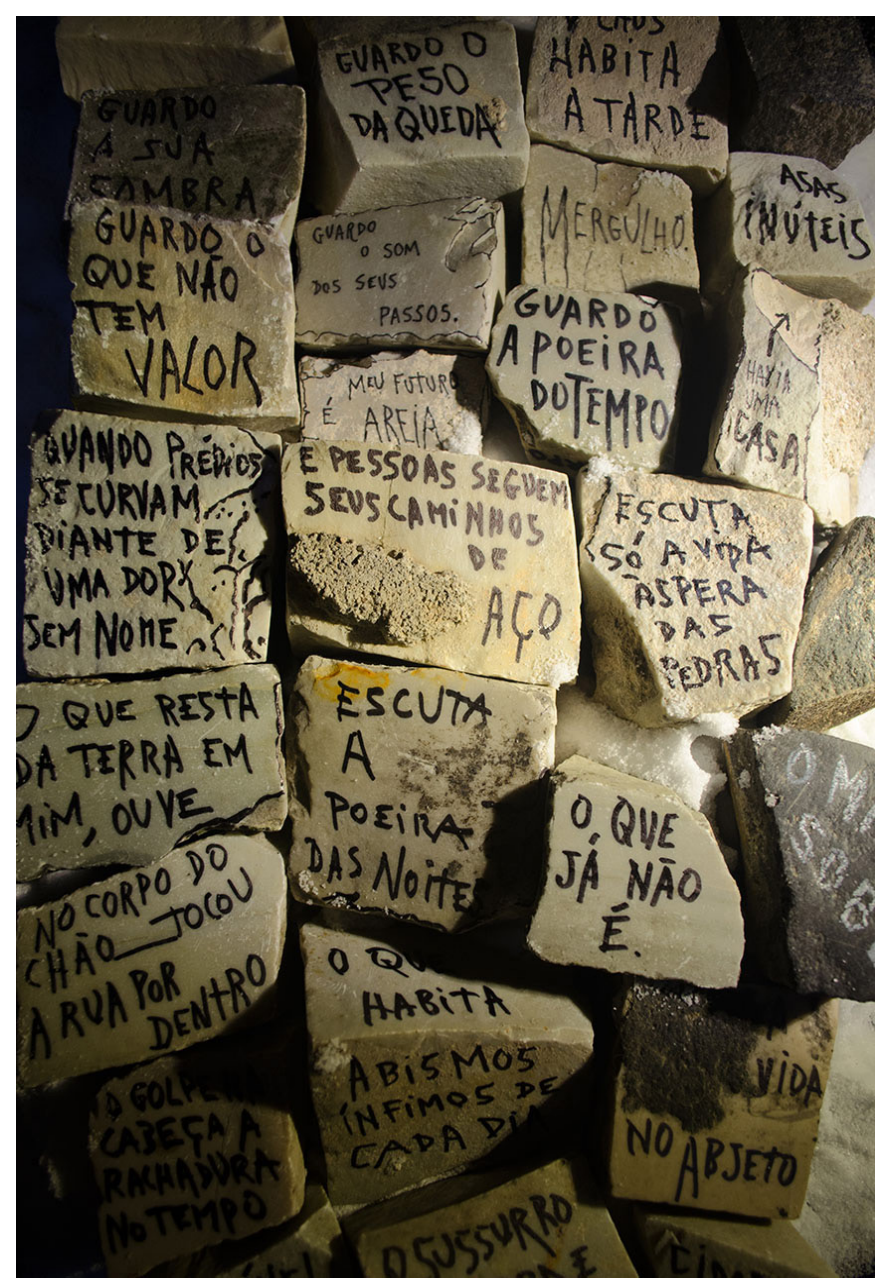

Figura 3. Detalhe de versão de Um Fardo de Palavras, 2016.

Richard Long, em suas peregrinações, colhe alguns itens matéricos dos caminhos que traça - tais como pedras dos Alpes - e posteriormente os apresenta em espaço expositivo, como testemunhas mudas e sólidas da sua experiência. Além dos eventuais mapas e fotografias, com títulos e legendas fornecendo dados sucintos e descritivos da caminhada, como "Dartmoor Riverbeds - A Four Day Walk Along all Riverbeds Within a Circle in Dartmoor, Devon, England, 1978", esses "pedaços de caminho" ajudam a restituir algo das experiências. Segundo Gilles Tiberghien, estes vestígios colhidos "constituem um sutil sistema de equivalência própria a nos mobilizar mentalmente em um trajeto; as linhas e círculos dispostas nos museus e galerias nos cativam a também caminhar, fisicamente, recapitulando algo desses gestos que Ihes deram forma" (Davila et al., 2000, p. 246). Em Walking Stones, Long desloca pedras de um ponto a outro de sua caminhada, considerando-as "agentes de mudança". Para realizar A Line of 33 Stones A Walk of 33 days, Ri- 
chard Long guarda uma pequena pedra para cada dia de uma caminhada de 1.030 milhas. Sobre esses deslocamentos, o artista afirma:

O mundo está continuamente em movimento geológico. A deriva continental acontece na velocidade em que nossas unhas crescem e partes da Grã-Bretanha se ergueram a partir do Atlântico Sul. Nada na paisagem é fixo; nada tem seu lugar "eterno". As pedras estão sempre se movendo por rios e glaciares, atiradas para fora de vulcões ou rolando montanha abaixo. Esses trabalhos em que movo pedras por aí são apenas uma outra parte deste continuum. (Long, 2007, p. 46).

Hamish Fulton, que resume sua prática com a afirmação "No walk, no work" (Sem caminhada, sem trabalho), não desloca nem retira nada dos caminhos pelos quais passa. Uma foto, algumas frases que acrescentam outras camadas à imagem - tal como "Seven days without talking" -, um breve roteiro de pontos-chave de sua jornada, talvez altitude, temperatura, é tudo o que recebemos de seus longos itinerários por locais solitários. Seu interesse não é por objeto algum, mas pelo gesto, por uma atitude. O artista declara que o que faz não é land art, que não pretende rearranjar o mundo, que sua arte é uma coisa e a natureza é outra - e esta deve ser respeitada. Acredita que a land art não tem esse respeito, que procura transformar a natureza - e que seu trabalho procura transformar a si mesmo (Fulton, 2014, p. 53). Afirma que se pode caminhar por uma paisagem sem sequer tirar uma fotografia ou escrever uma palavra - e ainda assim ser artista (Fulton apud Tiberghien apud Davila et al., 2000, p. 246).

As imagens que registram esses trajetos de Fulton têm uma certa neutralidade, são sóbrias, desprovidas de exuberância, evocam acontecimentos sutis, a passagem do tempo, referências a sons, texturas, brisas, acontecimentos, ínfimas sensações. Se Hélio Oiticica em seus "delírios ambulatórios" buscava as exaltações do "suprassensorial", Fulton parece desejar a experiência e a provocação de algo "infrassensorial". O artista tem a intenção de mostrar a natureza como acredita que deveria ser: intacta, e também sem os efeitos artificialmente obtidos do sublime; a natureza não conhece emoções ou moralidade, não há um desejo de impor quaisquer interpretações, daí a neutralidade de suas imagens. Fulton diz também que "a caminhada o torna mais receptivo à paisagem" (Fulton, 2014, p. 54). Gilles Tiberghien observa que em tudo se trata de uma postura "profundamente ética" que remete às "artes da existência" e às "técnicas de si" conceitualizadas por Foucault, transformando a própria vida em uma obra, de acordo com 
determinados valores éticos, estéticos, de estilo (Tiberghien apud Davila et al., 2000, p. 248).

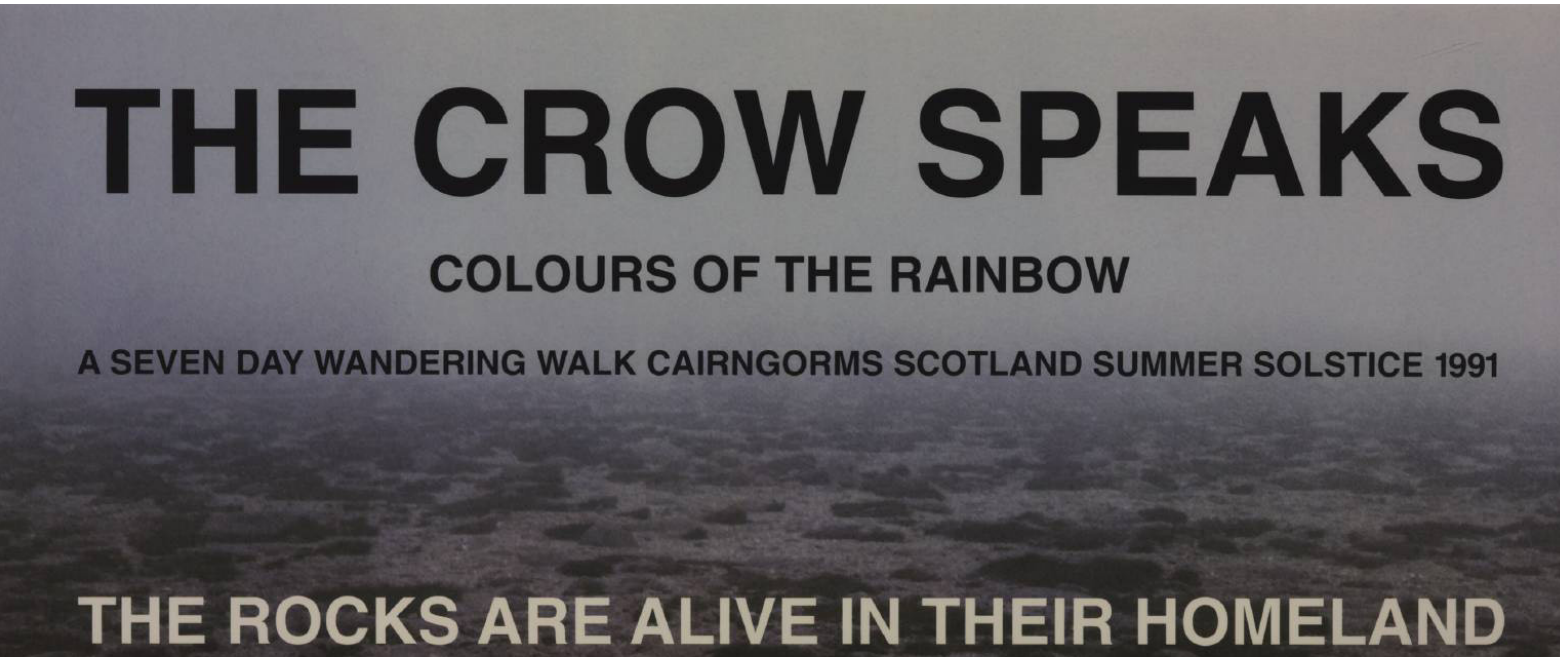

\section{SOLSTICE FULL MOON}

\section{A SEVEN DAY CIRCULAR WALK CAIRNGORMS SCOTLAND JUNE 1986}

Figura 4. Hamish Fulton, The Crow Speaks, 1991.

\section{Fronteiras, nomadismos, migrações (e confinamentos)}

O belga residente no México Francis Alÿs é um dos artistas que vaga, um exímio catador que exerce o nomadismo poético sob diversas formas e pretextos, tocando nas mais diversas questões. Já se colocou como Turista (1994) profissional entre trabalhadores que oferecem seus serviços em ruas da Cidade do México, já caminhou com Sapatos Magnéticos (1994) que funcionavam como um dispositivo "catador" de lixos e restos metálicos, incorporando parte da cidade, e já pintou, caminhando com uma lata de tinta furada, uma linha de respingos verdes para traçar visualmente The Green Line (2004) em Jerusalém. Alÿs transita, assim, do humor com que pode encarar seu trabalho como artista nômade à seriedade política de questões como fronteiras no Oriente Médio (Godfrey et al., 2010). O artista acredita que "os atos poéticos, em contextos e situações políticas extremas, podem provocar uma leitura distanciada de uma situação presente demais, gerando uma forma de mediação" (Alÿs apud Speer, in Buffet, 2012, p. 157). 
Em The Loop (1997) Alÿs se propõe a fazer o trajeto de Tijuana, no México, até a vizinha San Diego, nos Estados Unidos, sem passar pela problemática fronteira. Estabelece uma rota circular pelo Oceano Pacífico, parando em 15 cidades, em um trajeto de 29 dias que passa pela América Central, América do Sul, Oceania, Ásia, Alaska: saindo do México, transita pelo Panamá, Santiago do Chile, Auckland, Sydney, Singapura, Bangkok, Rangoon, Hong-Kong, Shanghai, Seul, Anchorage, Vancouver, Los Angeles e, finalmente, chega a San Diego (Davila, 2002, p. 19). Com a execução desse itinerário absurdo, o artista questiona a desigualdade que habita as fronteiras e, em consequência, a suposta "liberdade nômade": quem tem essa liberdade? A liberdade de trânsito é generalizada, o "direito de ir e vir" é igual para todos? É evidente que não. Para atravessar uma mesma linha imaginária, uma fronteira muitas vezes estabelecida através da guerra, da imposição violenta e do domínio econômico, basta estar em lados opostos para que a situação seja radicalmente diferente. A nacionalidade, a cor da pele, as origens étnicas, o sexo ou o gênero, a classe social: cada marcador desses pesará como uma diferença a mais na hora de atravessar uma fronteira. Um americano branco, uma mexicana indígena: diante da mesma linha instituída pelo poder, são situações absolutamente desiguais.

Assim, quando se faz um elogio do nomadismo, quando se fala em como a mobilidade se transformou em uma regra social planetária e o "artista nômade" é uma figura praticamente canônica na arte de hoje, cabe sempre perguntar: a quem é permitida toda essa variedade de trânsitos e movimentos relativamente livres? Quais pessoas e quais artistas realmente podem participar de todo esse nomadismo emancipador? De fato, esse tipo de mobilidade libertária só pode ser exercida por bem poucos, com base nos marcadores citados acima; e o que possui maior liberdade de movimentos é o típico homem branco europeu ou norte-americano em situação econômica confortável. Este é o indivíduo que tem fácil acesso aos mais diversos meios e fronteiras, que dificilmente desperta suspeitas em alfândegas, que raramente é abordado pela polícia, que está menos sujeito a violências; que viaja, não se refugia. Que tipos de trânsitos outras pessoas exercem, quais obstáculos, riscos e vicissitudes encontram pelos seus caminhos? 
Ao se abordar questões da mobilidade e do nomadismo, cabe pensar em como isso se dá para pessoas de diferentes origens, em regiões diversas do planeta, sem partir desse "pressuposto universal" que ainda é o "homem branco de origem europeia", o "humano" considerado pelo "humanismo" tradicional. Uma mulher afegã não tem a mesma possibilidade de se locomover que um homem afegão ou uma mulher francesa branca; esta tem mais facilidade para transitar que outra francesa de origem árabe, assim como um norte-americano louro e um negro não são vistos de maneira semelhante em seus trânsitos - ou encarceramentos.

Em um trabalho realizado pela artista e contadora de histórias Juliana Franklin, com crianças e adolescentes na Favela da Maré e no Complexo do Alemão, me foi relatado que muitas jamais haviam saído da favela, nunca haviam visto nada diferente daquele ambiente; e que o lugar mais distante e mais bonito a que algumas tinham ido era a Avenida Atlântica, em Copacabana, na mesma cidade, a poucos quilômetros. Tais crianças e adolescentes tinham dificuldades em sonhar e em imaginar algo diferente para suas vidas porque nunca tinham vivido nada diferente, não havia referência alguma além do que viam nas TVs, como uma inalcançável ficção.

Na verdade, ao se considerar a maioria da população, vivemos em um planeta de fronteiras violentas, impedimentos, clausuras, vidas estagnadas e encurraladas em guetos, periferias e favelas, trânsitos forçados, náufragos e refugiados que cada vez menos encontram refúgios.

Mathieu Pernot aborda muitas dessas questões em seus trabalhos: nomadismo, encarceramento, migrações, precariedade de refúgios. Em Les Migrants (2010), fotografa migrantes e refugiados dormindo nas ruas e em parques da França, enrolados em cobertores e panos no chão ou em bancos de praça, sem rosto e vulneráveis, quase como cadáveres, fantasmas ou coisas; Pernot torna visível algo desses "invisíveis". Em Promenades e Panoptique (2001 - 2002) Pernot fotografa, em um preto e branco cinzento, espaços destinados a caminhadas e banhos de sol dentro das prisões.

Georges Didi-Huberman observa, no texto em forma de carta que abre o catálogo da exposição de Pernot no Jeu de Paume: "Nosso olhar, confrontado a essa imagem, parece não encontrar saída. O 'pátio de exercícios' não passa de uma versão levemente maior que uma cela ou jaula". No entanto, como o autor observa, alguns 
elementos sugerem linhas de fuga, a possibilidade de "sair do cinza", dessa cor morta que domina esses ambientes: as bolas de futebol sobre uma grade parecem "zombar de toda essa imobilidade imposta"; e a palavra revolution está gravada na parte central de um muro, "desafiando a subserviência às regras da prisão".

Finalmente, há algo vivo em uma fotografia, algo que brota e cresce pelas brechas do terreno. Na imagem, essas plantas que se infiltram são tão cinzas quanto o resto: "[...] mas nós sabemos que elas saem do cinza do chão como uma possibilidade de vida, vida obstinada respirando sob a luz do sol" (Didi-Huberman apud Pernot, 2014, p. 6-7). As autoridades dos estabelecimentos penais não permitiram que Pernot fotografasse os presos: o que vemos de suas existências, de sua humanidade e de seus corpos são os vestígios que deixam, os traços gravados nas paredes. Segundo o próprio artista:

O que deve ser considerado nas fotos é o que nós não vemos, o que permanece fora da imagem... Mas se essas imagens não mostram os detentos diretamente, elas registram os sinais visíveis, os indícios deixados por aqueles que não vemos. Os muros dos pátios de exercícios estão salpicados de grafites, desenhos, mensagens escritas pelos detentos. Eles são superfícies sensíveis genuínas, espaços de inscrição que Ihes permite fixar suas presenças, registrar o fato de que, um dia, passaram por ali. Gravar algumas palavras na pedra ou no concreto é um ato muito próximo do registro fotográfico: é um modo de deixar rastro, de afirmar "isso aconteceu", "eu estive ali". Muitas vezes os presos escrevem um nome, uma data ou um lugar, como se quisessem escrever a legenda de uma foto que jamais será tirada. (Pernot, 2014, p. 11-12).

Diante dessa impossibilidade de fotografar os presos, Pernot criou outra série, Les Hurleurs (Os gritadores, 2001-2004), em que fotografou parentes de detentos do lado de fora das prisões, no ato de um grito, um chamado: o som atravessa fronteiras, invade espaços proibidos, cria contato na distância. O grito também é uma forma de "resistir à violência do confinamento a que eles também estão submetidos" (Didi-Huberman apud Pernot, 2014, p. 16). Um desses gritadores, Jonathan, foi antes uma criança que também aparece em outras séries do artista, séries em que Pernot acompanha grupos de ciganos, em trabalhos que geram intrincados questionamentos e problematizações, como Un Camp Pour Les Bohémiens (19982006). Pernot, além de realizar registros fotográficos e mapas de percurso, se utiliza de controversos arquivos fotográficos do governo, realizados com o intuito de classificar, marcar e controlar esse povo. Isso expõe que, ao contrário do elogio intelectual do nomadismo libertador, a realidade que os ciganos encontraram foi 
e é bem diferente: sempre marginalizados, estudados como objetos pela ciência racista do séc. XIX, relegados a campos de concentração, perseguidos, expulsos, presos, mortos. É o povo que não deixa rastros, como no poema de Brecht"; "onde os povos sedentários arquivam, conservam e exibem a sua história, os ciganos enterram, queimam e fazem desaparecer os traços de sua passagem. O silêncio dos ciganos é uma das figuras dessa não inscrição" (Pernot, 2014, p. 27). Essa característica de invisibilidade e silêncio que o povo cigano busca torna o trabalho com arquivos, por si só, algo paradoxal; mas Pernot trabalha com esse paradoxo, como se todos fossem "gritadores" e ele se juntasse a esse grito, construindo uma "caixa de ressonância" para levá-lo mais longe, até onde o elogio do nomadismo tantas vezes se esquece dos migrantes reais. Jonathan, criança nômade em 1995 e gritador chamando um parente dentro de uma prisão em 2001, torna-se detento em 2013, preso por ter cometido um furto. Como diz Didi-Huberman:

Os ciganos cruzam fronteiras a pé e nesse caminho roubam alguns quilos de cobre numa ferrovia europeia, enquanto homens de negócios cruzam fronteiras também, mas de avião, com a finalidade de comprar, em algum lugar da África, uma ou duas minas de cobre. Migrantes se afogam no mar em Lampedusa, passando por turistas que se dirigem a Malta, Djerba ou Ilhas Ionianas [...] Os migrantes migram para algo melhor - escapar de um país em guerra, arrumar um emprego e poder comer apropriadamente - ou para pior - vagando infindavelmente pela Europa que, entre a ânsia por vigilância e um discurso de benevolência, os rejeita por todos os lados ou os confina a acampamentos, impedindo que tenham qualquer chance de obter as condições mínimas para uma vida decente. (Pernot, p. 28).

Que essas pessoas que não são o "homem branco" passem a experimentar cada vez mais a liberdade de trânsito e de fluxos, que tenham como se emancipar através de experiências estéticas, de nomadismo e de sensibilização, que possam se reconhecer e serem reconhecidas por outrem em um mesmo patamar de humanidade que o "homem branco" é o que de fato mais importa nessa questão.

\footnotetext{
7 "Apague os Rastros", de Bertold Brecht, em "Manual para os Citadinos"; segue-se o trecho final: "[...] Coma a carne que aí está. Não poupe./ Entre em qualquer casa quando chover, sente em qualquer cadeira/ Mas não permaneça sentado. E não esqueça seu chapéu./ Estou Ihe dizendo:/ Apague os rastros!/ O que você disser, não diga duas vezes./ Encontrando o seu pensamento em outra pessoa: negue-o./ Quem não escreveu sua assinatura, quem não deixou retrato/ Quem não estava presente, quem nada falou/ Como poderão apanhá-lo?/ Apague os rastros!/ Cuide, quando pensar em morrer/ Para que não haja sepultura revelando onde jaz/ Com uma clara inscrição a Ihe denunciar/ E o ano de sua morte a lhe entregar/ Mais uma vez:/ Apague os rastros!/ (Assim me foi ensinado.)".
} 


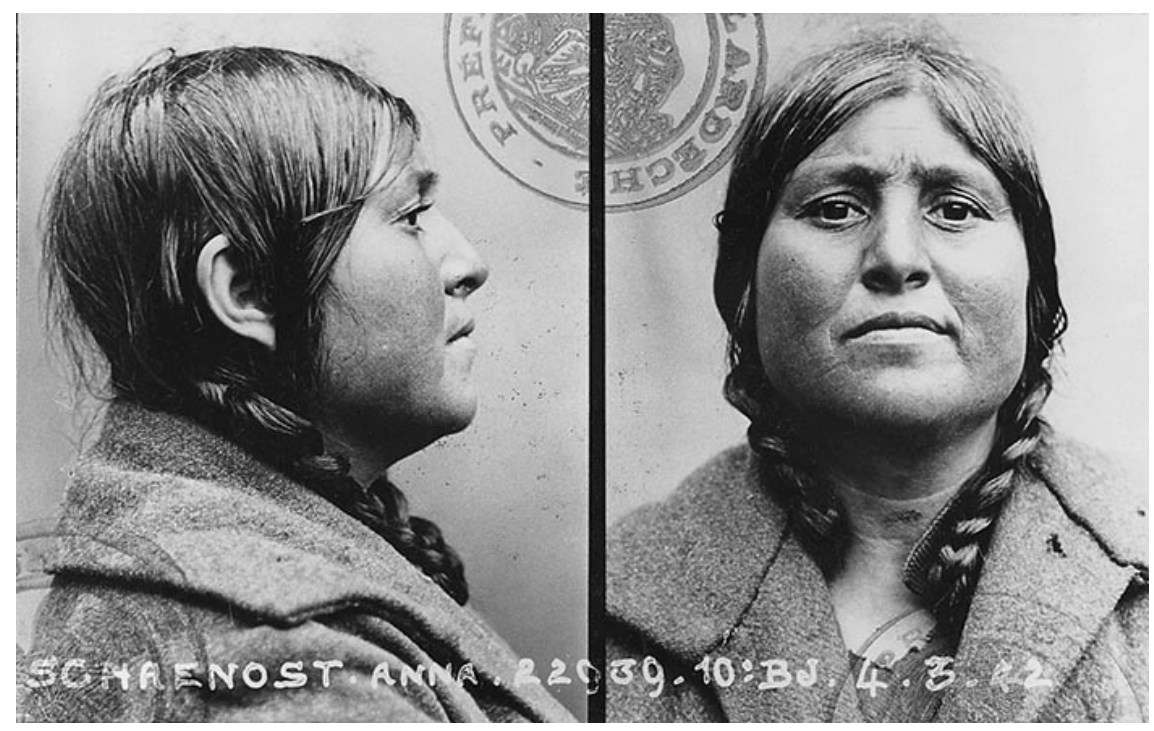

Figura 5. Mathieu Pernot, fotografias da série Un Camp Pour Les Bohémiens, 1998-2006.

\section{Cut-up Tragedy: ocupando espaços em um projeto-processo nômade}

Em minha própria vivência nas caminhadas pelas cidades, seguindo sons e conversas, mensagens fragmentadas escritas pelas paredes, rastros e asperezas deixados nas superfícies, eventualmente experimentei interdições, espaços perigosos e zonas proibidas; muitas vezes ignorando e transgredindo os limites, surgiu uma nova série, Cut-up Tragedy. ${ }^{8}$

As ruas de cada cidade falam: não só através das vozes de seus habitantes e dos ruídos de seus trânsitos e movimentos, mas também através dos escritos em seus muros, placas e calçadas, das cenas vividas e testemunhadas, da história marcada ou apagada em sua arquitetura e urbanismo, do subtexto presente em seus hábitos e códigos de convivência. Desde criança imagino encontrar respostas para coisas que estou pensando ao ver algo escrito na cidade, por acaso, quando estou em algum trajeto; até que isso também virou um método para compor textos, músicas, imagens. Ao explorar a riqueza de cada lugar - e as diferenças, semelhanças e dissonâncias entre os lugares -, cada esquina, cada muro, prédio, terreno baldio, cada pedaço de cidade oferece uma multiplicidade de possibilidades poéticas (e políticas).

8 A parte final deste artigo, sobre o projeto Cut-up Tragedy, teve uma versão prévia e reduzida publicada na Linda NME, uma revista on-line sobre pesquisa em música e som, independente, não indexada. 
Da observação e experiência caminhando por diferentes bairros e cidades, em 2015 desenvolvi, como processo e projeto, o "cut-up tragedy", aplicável a diversos contextos urbanos. O início do trabalho surgiu em derivas por Nova York em 2014 - na época em que fui executar NYC Ghosts and Voices ${ }^{9}$-, especialmente pelo sudeste de Manhattan e por diversas regiões do Brooklyn, principalmente em áreas de imigração latino-americana. O projeto mantém uma ligação com esse meio no qual despertou, com a arte de rua nas metrópoles, com o punk e o hip-hop, com os guetos. Referências beatniks, dadaístas e surrealistas já se mostram no termo "cut-up": a origem remete a "Como fazer um poema dadaísta", de Tristan Tzara, montado com trechos randômicos, "tirando palavras de um chapéu"; e Brion Gysin e William S. Burroughs reelaboraram a técnica anos depois. Gysin redescobriu o método, como não poderia deixar de ser, por acaso: ao usar uma proteção de camadas de jornais sobre a mesa para realizar cortes em papel, acabou "cortando" poemas aleatórios. Gysin e Burroughs aplicaram variações dessa técnica, inclusive em áudio, editando gravações em fita. Burroughs também considerava os cut-ups uma forma de divinação: "When you cut into the present the future leaks out" (Quando você corta o presente o futuro vaza). O escritor também pesquisava efeitos virais da linguagem, das imagens e do som, principalmente infrassons, "para provocar revoltas" (Goodman, 2010, p. 24). A influência desses processos se estende na música até hoje, passando pelo campo experimental e industrial do final dos anos 1970, com Laurie Anderson, Cabaret Voltaire e Throbbing Gristle, até artistas mais populares, como Bob Dylan e David Bowie.

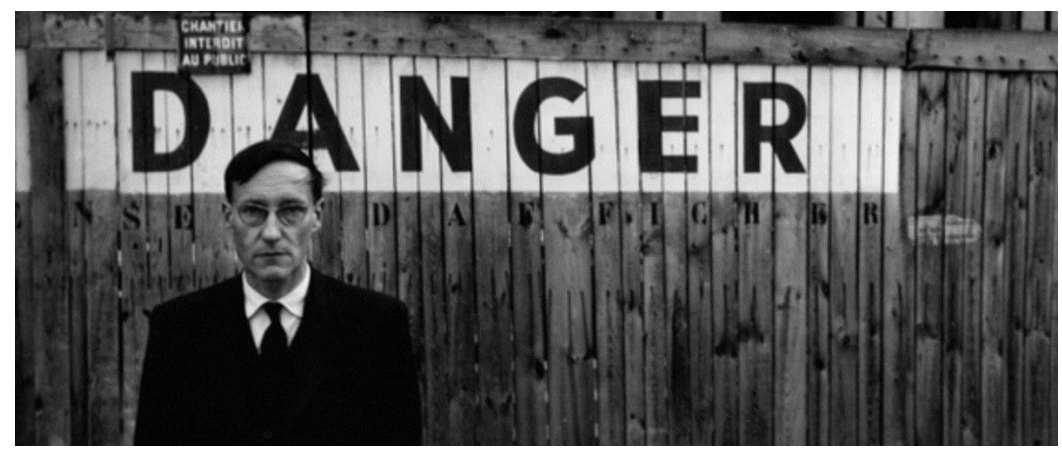

Figura 6. Retrato de William Burroughs, Danger Series, Naked Lunch series. Fotografia de Brion Gysin em frente ao Théâtre Odeon, Paris, 1959.

9 Composição de 31 minutos feita a partir de excertos sonoros relativos à memória da cidade de Nova York, especialmente focada nos indígenas nativos, os Lenni Lenape, que falavam o Munsee, língua praticamente extinta; a composição serve de guia para uma caminhada sonora pelo sudeste da ilha. A primeira caminhada coletiva se deu no contexto do Convergence 2014, evento realizado pelo Hemispheric Institute com o apoio da Columbia University e da NYU. 
O Cut-up Tragedy é um multiprocesso-projeto nômade que experimenta, transforma e gera matérias sonoras, imagens, palavras e amálgamas de fragmentos. Sua realização depende dessas livres caminhadas já abordadas, em um estado de crescente "desregramento dos sentidos", o texto urbano como extensão e rastro de mãos que tatuam as cidades, os vestígios de corpos que passam, cortes no espaço-tempo, a experiência de um tempo trágico. São caminhos entre mundos, espaços expandidos por camadas temporais e fantasmáticas de memória e esquecimento, lugares entre o passado, o instante e as possibilidades futuras, passagens entre história e ficção, mergulhos psicogeográficos, naufrágios micro-geo-políticos.

Em Atlântica, processos similares estão fortemente ligados a origens, identidade, história, a um vínculo com lugares específicos; nas Cartas de Terras Insondáveis esses processos não dependem de meus próprios vínculos e questionamentos sobre origens: a relação é com a experiência, a escuta e a pesquisa do lugar, de qualquer lugar; mas os processos têm um tempo lento de aprofundamento e maturação. Cut-up Tragedy é o mais nômade, fluido, urbano e desterritorializado dentre os três processos-séries: aqui o ritmo é rápido e incisivo, a profundidade é a da pele das cidades, corte veloz e cinematográfico de quem está de passagem mas busca vislumbrar esse reluzir desestabilizante nos espaços e colher alguns rastros deixados por outros corpos.

O conceito de cut-up não se aplica apenas à técnica de montagem que entrega a linguagem a novas ordens e desordens do acaso: o cut-up aplica-se aos cortes que as sincronicidades imprevistas e descontinuidades caóticas provocam na percepção do real, do concreto. Um caminho nunca é o mesmo caminho, um caminho é feito de muitos caminhos. O presente se altera pela presença de outros tempos.

Este processo de derivas e cut-ups resulta em séries de trabalhos com fotografias, textos, contaminações entre arte pública e nas galerias, livros, composições-performances musicais. Gravador microfonado, câmera fotográfica e um bloco de anotações são as ferramentas iniciais, os meios para amplificar as experiências, colher algumas impressões e coletar os fragmentos que vão compor os trabalhos finais. Posteriormente, aplico variações da técnica cut-up, colagens e camadas sobrepostas a diferentes matérias: gravações de campo, fragmentos textuais lidos ou ouvidos pelas ruas e cenas testemunhadas nas derivas. O texto encontrado em 
uma cidade também é deslocado para outra: em sons, na palavra escrita e falada, em imagem, em ruídos. Cartazes feitos a partir de fotos e textos de uma cidade são colados em outra. A música de um lugar se mistura à música de outro lugar, dois ambientes criam um terceiro espaço sonoro, a ficção de uma cidade feita de elementos de outras cidades. O material sonoro, visual e textual pode ser apresentado de diferentes maneiras ao fim de cada etapa: vídeos, cartazes, um livro, um álbum musical, um show/concerto, uma mistura de tudo isso.

A composição-performance musical é realizada tendo como base gravações de campo feitas nessas caminhadas e derivas. Tais gravações são editadas, processadas e reprocessadas até o ponto de gerarem drones e um "wall of noise". A voz é improvisada e processada ao vivo, lendo ou cantando em diversas línguas e em glossolalias laicas - muitas vezes usando traduções automáticas que geram erros insólitos então incorporados ao texto original. Dou voz à mistura de fragmentos textuais encontrados pelas ruas, compondo meu próprio texto com alguns roubos, autorias múltiplas e irrastreáveis. Também interfiro e tatuo superfícies com meu texto, minha voz. As vozes se juntam a gravações de campo de diferentes cidades. Essas gravações são alteradas, e outras camadas se somam ao vivo: improvisos de voz passando por loopers e efeitos que podem multiplicar uma voz feminina em muitas - ou torná-la masculina, ou ainda indefinível.

O texto é composto, em parte, usando a técnica do cut-up aplicada às superfícies urbanas: montado com palavras encontradas em muros, placas, jornais, calçadas. Todo o equipamento é sempre portátil, mesmo para realizar uma apresentação musical ao vivo: cabe em uma mochila, em sintonia com o conceito nômade do projeto. Os textos também são compostos muitas vezes como fabulações poéticas em torno de uma breve cena vista/ouvida/gravada/fotografada, tendo também como referência caminhantes de outras épocas, assim como os viajantes e imaginadores de cidades: Baudelaire flanêur, Nietzsche, o Rimbaud errante e vidente das Iluminações, Nerval, Benjamin e suas Passagens, Borges e Cortázar, João do Rio, Debord, As Cidades Invisíveis de Calvino, Kerouac, Burroughs e as Interzonas e Cidades da noite vermelha.

Surgem aí questionamentos sobre as implicações desses processos e do porquê, entre tantas referências históricas aos caminhantes, poetas e cronistas das cidades, inicialmente só ocorrerem nomes masculinos. A exceção se dá justamen- 
te em relação a práticas mais recentes envolvendo soundwalks, tecnologias de gravação e práticas da arte contemporânea ou do underground dos anos 1960 e 1970 em diante. Ao pensar sobre essas exceções, além da escritora Rebecca Solnit, surgem alguns exemplos bastante distintos entre si: Hildegard Westerkemp, Yoko Ono, Janet Cardiff e nomes ligados à cena experimental, punk e no-wave de Nova York, como Laurie Anderson, Patti Smith e Lydia Lunch - todas referências das mais importantes.

Antes da ascensão do feminismo e da contracultura, mulheres que adotavam as ruas das cidades como um de seus espaços privilegiados de experiência e de fazer artístico não eram exatamente uma possibilidade. O beatnik dos anos 1940, 1950 e 1960 pode ser um interessante meio a observar, constituindo um momento de eclosão de comportamentos fora do padrão "feminino" tradicionalmente imposto, desejoso de rua, estrada, liberdade. Havia exceções entre as mulheres beatniks, como Diane Di Prima, Anne Waldman e LouAnne Henderson - que conseguiram levar vidas relativamente livres, ainda que jamais tenham tido as mesmas oportunidades e o mesmo destaque que seus pares masculinos. É igualmente importante perceber que, mesmo nesse meio, podiam predominar as imposições de uma sociedade estruturalmente machista. As mulheres chegavam a ser internadas como doentes mentais, como Elise Cowen. Conforme relatou Gregory Corso, citado por Cláudio Willer em Geração Beat:

Houve mulheres, estiveram lá, eu as conheci, suas famílias as internaram, elas receberam choques elétricos. Nos anos de 1950, se você era homem, podia ser um rebelde, mas se fosse mulher, sua família mandava trancá-la. Houve casos, eu as conheci, algum dia alguém escreverá a respeito. (Corso apud Willer, 2009).

Para uma mulher, fazer das ruas um tema e um território próprio a experiências intensas e a práticas da arte e da escrita tinha uma estreita relação com a loucura. Ainda hoje, quando uma mulher é agredida ou violentada na rua, é constantemente culpabilizada: "O que estava fazendo naquele lugar, àquela hora, com aquela roupa?". Poderia estar voltando da escola dos filhos, ao meio-dia, coberta dos pés à cabeça e ainda assim alguma desconfiança mórbida e misógina recairia sobre sua presença caminhando pelas ruas. A mensagem velada, o subtexto da estrutura patriarcal é: "A rua não foi feita para as mulheres, o espaço público não Ihes pertence, os corpos e as vozes femininas não devem aparecer e ter significado independentemente de suas funções em relação ao homem, o lugar da mulher 
é em casa, seu espaço é o privado, doméstico, controlado, restrito". Este espaço doméstico é considerado inferior: construído e organizado para ser despolitizado, colocado fora da esfera das decisões de ordem social e da participação cultural. Se considerarmos outras culturas contemporâneas, como a dos países muçulmanos, o espaço de respeitabilidade reservado à mulher ainda é quase que exclusivamente o doméstico.

QUERO VESTIR E SAIR

Quero vestir e sair e subir em um ônibus pegar um cheque e declarar um

seguro desemprego.

Corpo, porque essa sensação esquisita - pavor

De que -

Morte? Morte tanto desejada?

"Morte da mente" - paz - não a dissolução a sete palmos.

(Cowen, 2014).

O desejo de "vestir e sair e subir em um ônibus" é bem menos prosaicamente realizado sem consequências indesejáveis por uma mulher do que por um homem. As experiências de andar livremente pelas cidades e escrever suas impressões sobre elas costumam vir majoritariamente de homens porque a circulação das mulheres é historicamente regulada, em diferentes graus restrita a espaços "seguros" e "domésticos". De fato, pode ser perigoso caminhar sozinha pelas cidades, especialmente à noite: assim como pode ser perigoso co-habitar com um agressor familiar. Qual é a ameaça, o espaço ou o agressor? Por que se regula o espaço, não o agressor?

O que se pretende regular, controlar e submeter é, mais uma vez, o corpo feminino e a amplitude da experiência das mulheres e de sua expressão no espaço público e na sociedade. A questão da mobilidade relacionada ao sexo, ao gênero, é também uma questão política. $\mathrm{O}$ trabalho de Shirin Neshat e a análise de Ferzaneh Milani me foram fundamentais para pensar o que ocorre, seja no Oriente ou no Ocidente, seja em uma grande cidade, no campo ou em alto-mar:

A alocação espacial definida pelo gênero, no entanto, tem uma extensa relevância e a vontade de limitar o espaço das mulheres não é peculiar a uma cultura ou a outra. Sancionadas por noções de beleza, desejo, segurança, moralidade ou religião, muitas culturas têm restringido a mobilidade das mulheres. (Milani apud Neshat, 2001, p. 9). 
O trânsito dos corpos femininos é historicamente controlado, regulado, forçado, contido, sujeitado aos desejos, vontades, delírios de posse e medos masculinos. Ser mulher e exercitar a cada dia a experiência do livre trânsito pelos espaços públicos pode parecer simples e prosaico, mas é na verdade uma conquista a ser preservada e reafirmada. Caminhar livremente pela cidade é também questionar as noções de que o perigo está em determinados lugares, de zonas proibidas, de regulação dos espaços em nome da "segurança": é transgredir fronteiras, desafiar a alocação espacial definida pelo sexo, pelo gênero, é gerar ideias e matérias a partir da experiência desse desafio. A cidade também permite brechas, linhas de fuga, desvios, escapes, esconderijos.

O nome Cut-up Tragedy foi pensado primeiramente com um sentido duplo: de enfatizar uma experiência trágica-dionisíaca-nietzscheana da vida e a influência/uso de técnicas de cut-up; e um segundo movimento, de um paradoxal deboche ácido, em oposição à leveza tantas vezes forçada e exibicionista que percebo na vulgarização disso que se chama stand-up comedy, que tão bem pode refletir um desejo deseperado de felicidade eufórica e bem-estar total, a inaptidão para de fato enfrentar o mal-estar que a nossa sociedade vive. Cut-up Tragedy diz: "Não acho graça em toda essa alegria encenada sob os refletores. Não acho graça na medicação compulsiva do mal-estar. Não acho graça que homens ainda tenham tantas liberdades que mulheres, na prática, não têm. Assim, procuro outras graças, outras alegrias, desviantes". No entanto, este nome-processo-projeto, no decorrer das experiências, ganhou um outro peso, menos cerebral-irônico, mais visceral: na relação concreta, corporal, física, com a possibilidade do corte e do trágico; e traçando uma ligação com o momento crucial das mulheres no movimento beatnik, entre o desejo-vivência de um "fora" e a limitação de movimentos, entre a realização da transgressão e o apagamento de suas identidades; na necessidade vital de existir, em liberdade, a cada instante.

O texto abaixo, intercalado a algumas das imagens que geraram o texto, é um desses trechos compostos a partir de pichações, placas, cartazes, sons, livres associações, sonhos e cenas em diferentes cidades, centros e periferias - Rio de Janeiro, Nova York, Paris, Barcelona, São Paulo. 
Guardo o que não tem valor

Mas sempre estivemos aqui

Agarrados nas entranhas das calçadas mútuas

Opacos, ouvindo todo dia o ruído que escapa

lá

Neste vão esquecido poros da parede traço de tinta aspereza e fumaça

Nossa pele pedra papel e tesoura - sorria, você está sendo

Respirar não é tão fácil assim

Ursinho de pelúcia enforcado em cinza

Gritam por aí "Más Paz!" com cores bonitas

Happiness we're AssKed

But I was shot by Billy Kidd

Tantas vezes que nem lembro

É de criança que se aprender a atirar

e morrer

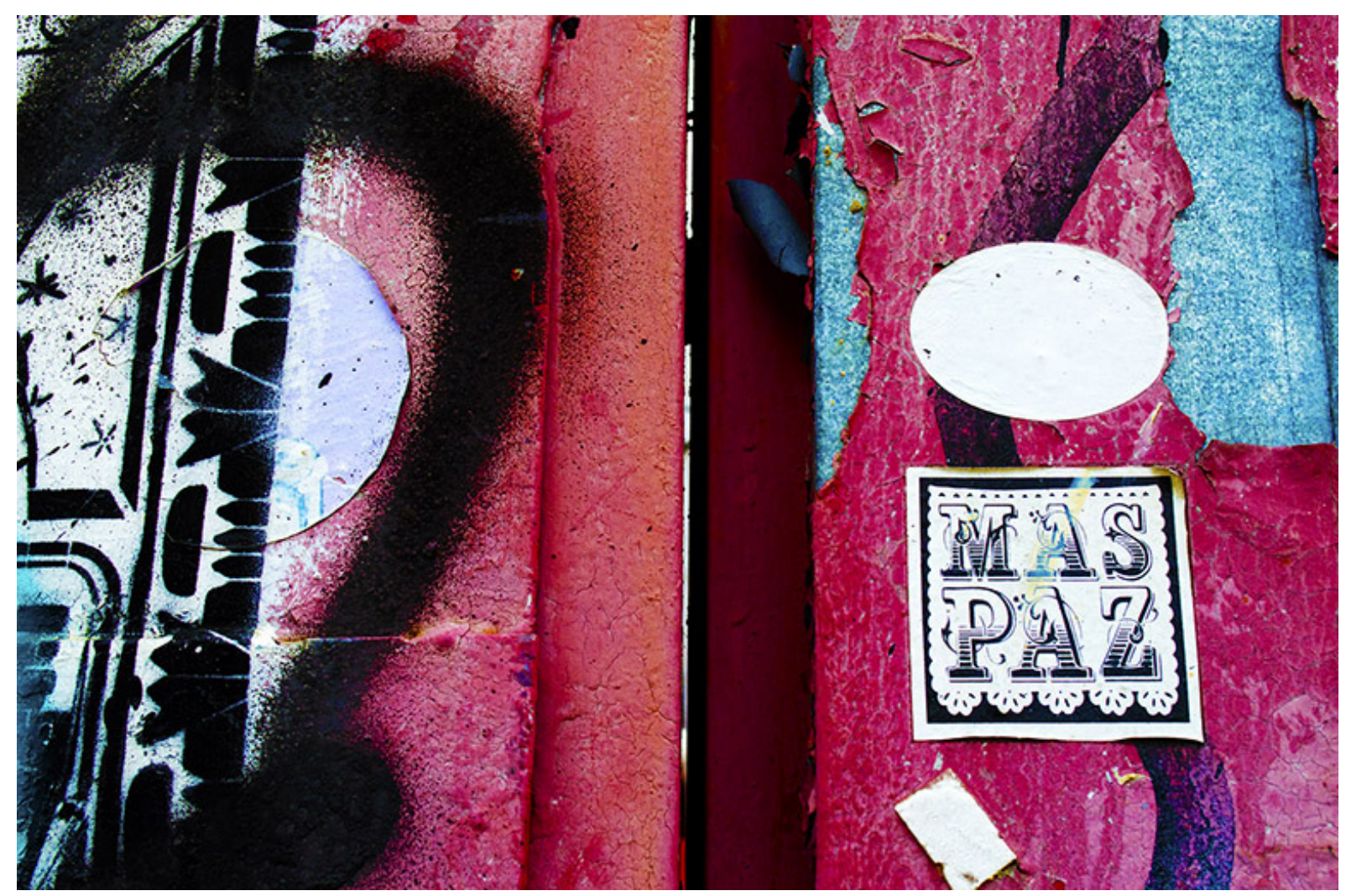

Figura 7. Fotografia da série-projeto Cut-up Tragedy, 2014.

\section{Bang Bang}

Shot by security video surveillance

XX Ray eyes

To the moon 

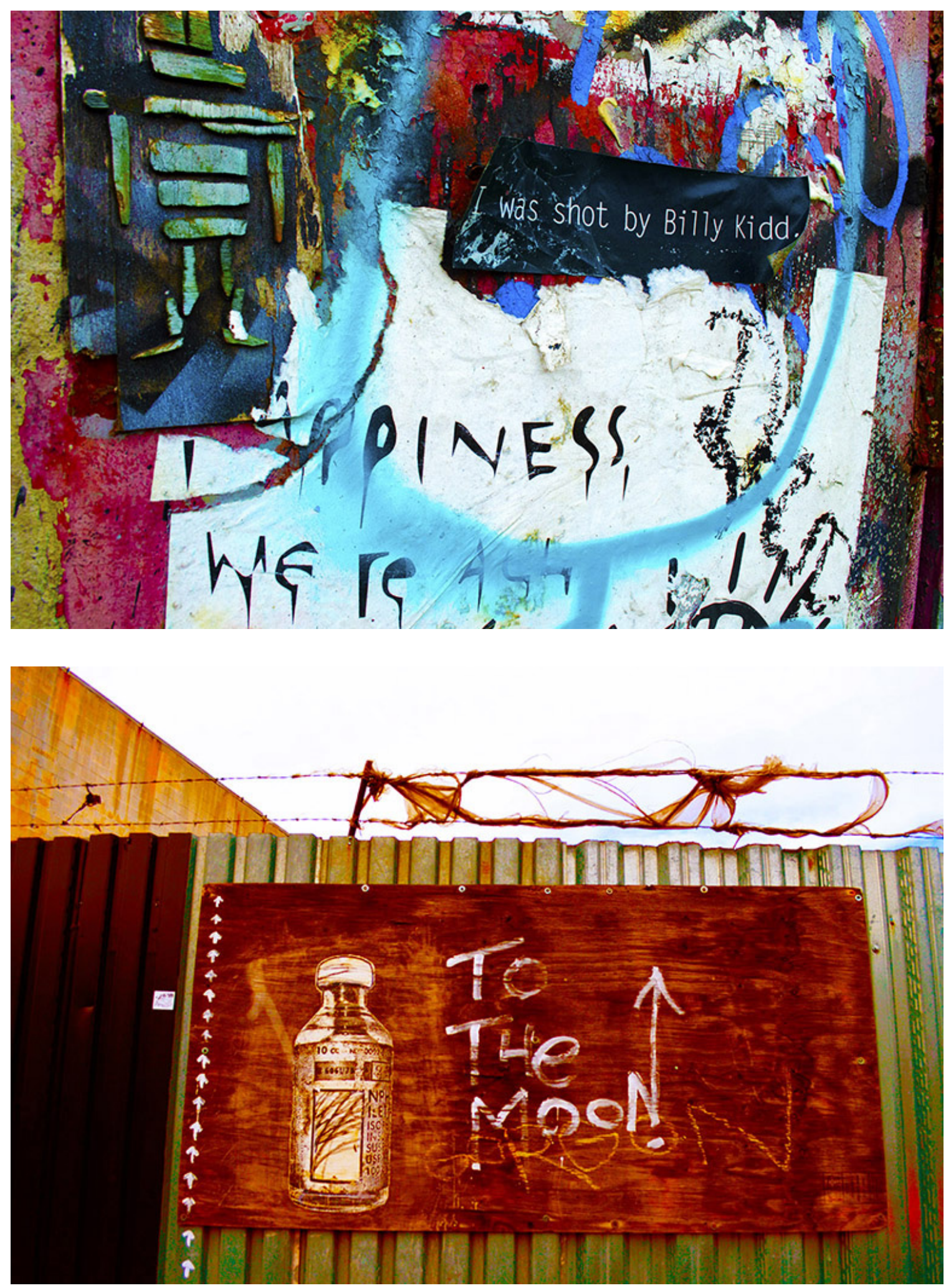

Figuras 8 e 9. Fotografias da série-projeto Cut-up Tragedy, 2014. 
www.go.org.on Gorgona

there is a thread that ties me to the night

To the moon
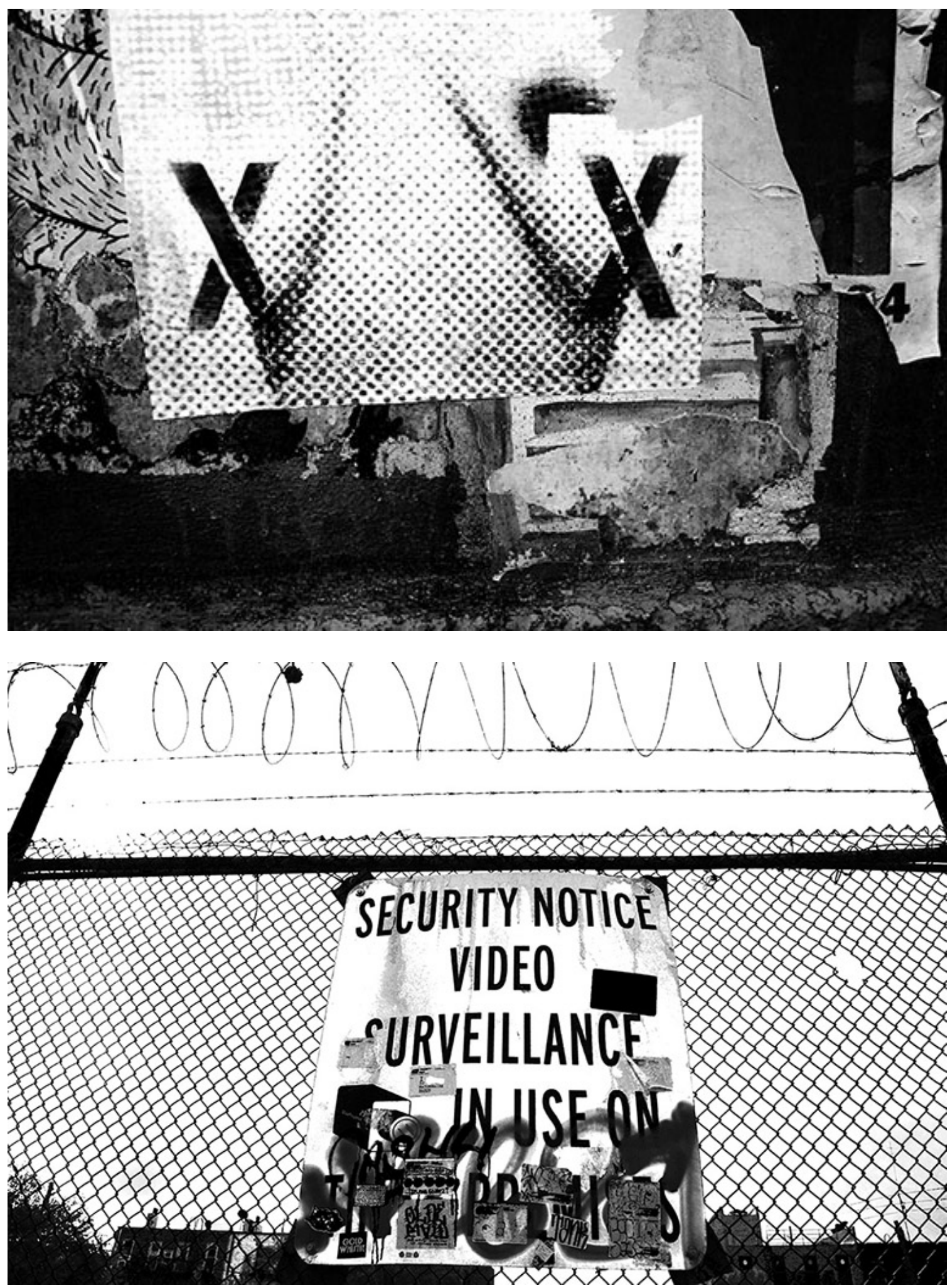

Figuras 10 e 11. Fotografias da série-projeto Cut-up Tragedy, 2014. 


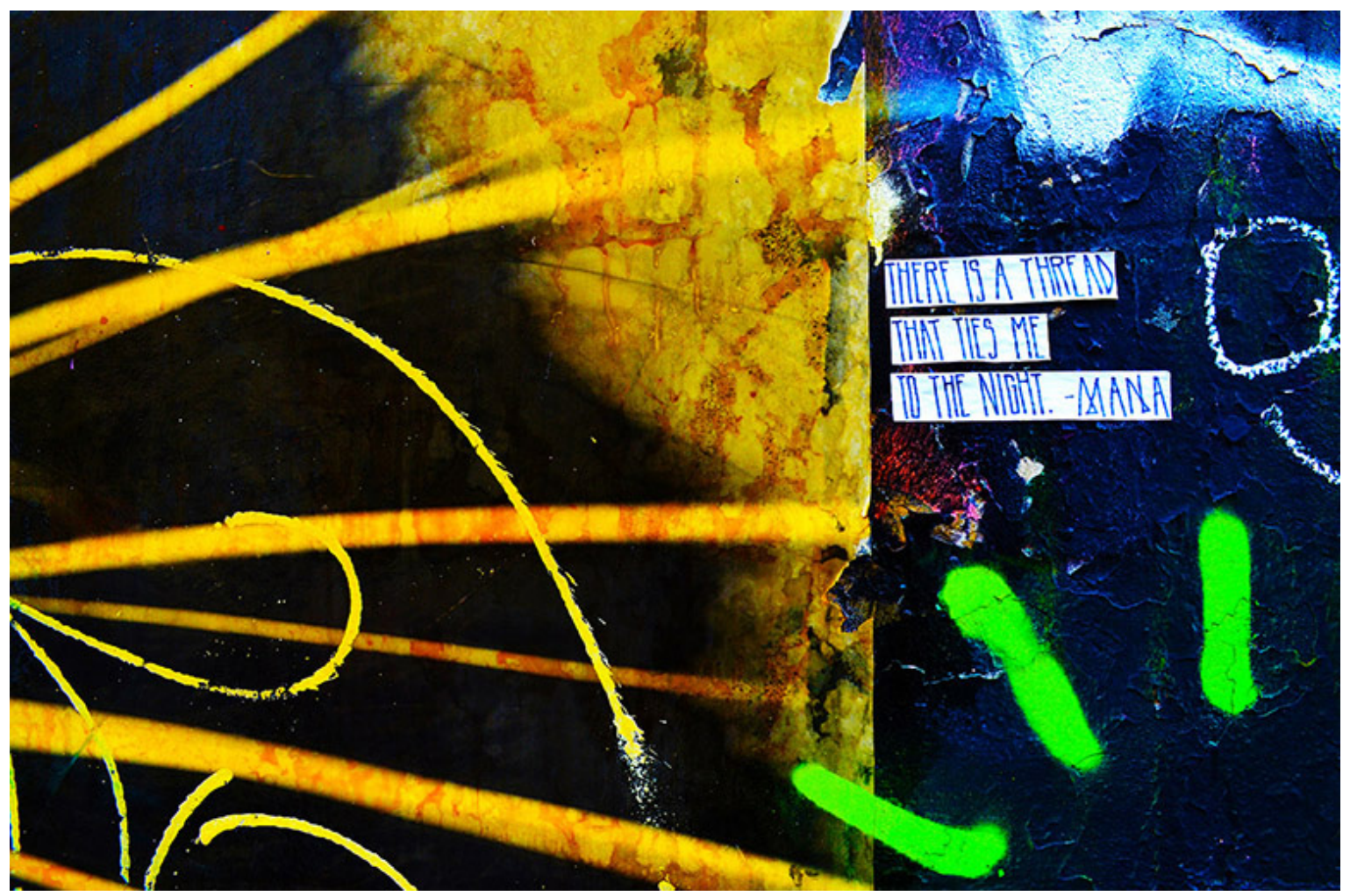

Figura 12. Fotografia da série-projeto Cut-up Tragedy, 2014.

Textos e imagens como esses fazem parte da montagem do livro Cut-up Tragedy - 1, inicialmente um e-book-zine, mas com o projeto de ser também impresso. A partir das primeiras experiências Cut-up Tragedy editadas junto a algumas das gravações iniciais de Atlântica surgiu também a primeira composição sonoro-musical do projeto, Occe Anna Tlant X-Cities, de cerca de 19 minutos de duração, que faz parte dos anexos sonoros.

Algumas dessas fotografias e textos estiveram na Déambulations Poetiques, exposição colaborativa junto a Isabel da Cunha e Ana Procopiak na galeria CP5 do coletivo Curry-Vavart, em 2015, em Paris. Na mostra, procuramos criar uma deambulação a partir das nossas próprias caminhadas, confundindo espaços, tempos, lugares, autorias. Isabel nasceu no interior do Brasil, mas já morou em diferentes locais do planeta, como Rússia e Oriente Médio, tendo vivido severas restrições no espaço público; Ana fotografava a partir de sua própria cidade, Curitiba; e eu fotografei a partir dessas derivas e viagens, desde a minha cidade natal, o Rio de Janeiro, até locais que conhecia pela primeira vez naquele momento. Nessa ocasião também realizei a primeira performance sonora do projeto: com o palco escuro, permaneci escondida atrás do público, na técnica, atrás da mesa de som. O som em si, alto e ruidoso, corpóreo, os atritos que gerava nos ouvintes e os espaços e imagens que poderia gerar eram a performance - tratava-se da minha voz como corpo, do corpo do som e dos corpos dos ouvintes. 
Pouco tempo depois algumas dessas imagens e textos estiveram em outra exposição, Braises d'Aujourd'hui, no Confluences, em Paris. Foram seis fotografias reproduzidas diversas vezes e impressas como adesivos em diferentes versões de tamanho e cor: colorido, preto e branco em alto contraste, preto e vermelho. Foram espalhadas pela galeria, incluindo partes normalmente "mortas", sobre portais, no bar, dialogando com o espaço arquitetônico de forma semelhante às escritas das ruas. Também relacionavam-se esteticamente ao trabalho de outro artista, Brice Maré, que realiza desenhos com fitas adesivas que interagem com a arquitetura e transformam a perspectiva dos espaços. A proposta da exposição era traçar diálogos, abertos a improvisos, entre artistas do Brasil e da Europa.

Pouco tempo depois algumas dessas imagens e textos estiveram em outra exposição, Braises d'Aujourd'hui, no Confluences, em Paris. Foram seis fotografias reproduzidas diversas vezes e impressas como adesivos em diferentes versões de tamanho e cor: colorido, preto e branco em alto contraste, preto e vermelho. Foram espalhadas pela galeria, incluindo partes normalmente "mortas", sobre portais, no bar, dialogando com o espaço arquitetônico de forma semelhante às escritas das ruas. Também relacionavam-se esteticamente ao trabalho de outro artista, Brice Maré, que realiza desenhos com fitas adesivas que interagem com a arquitetura e transformam a perspectiva dos espaços. A proposta da exposição era traçar diálogos, abertos a improvisos, entre artistas do Brasil e da Europa.

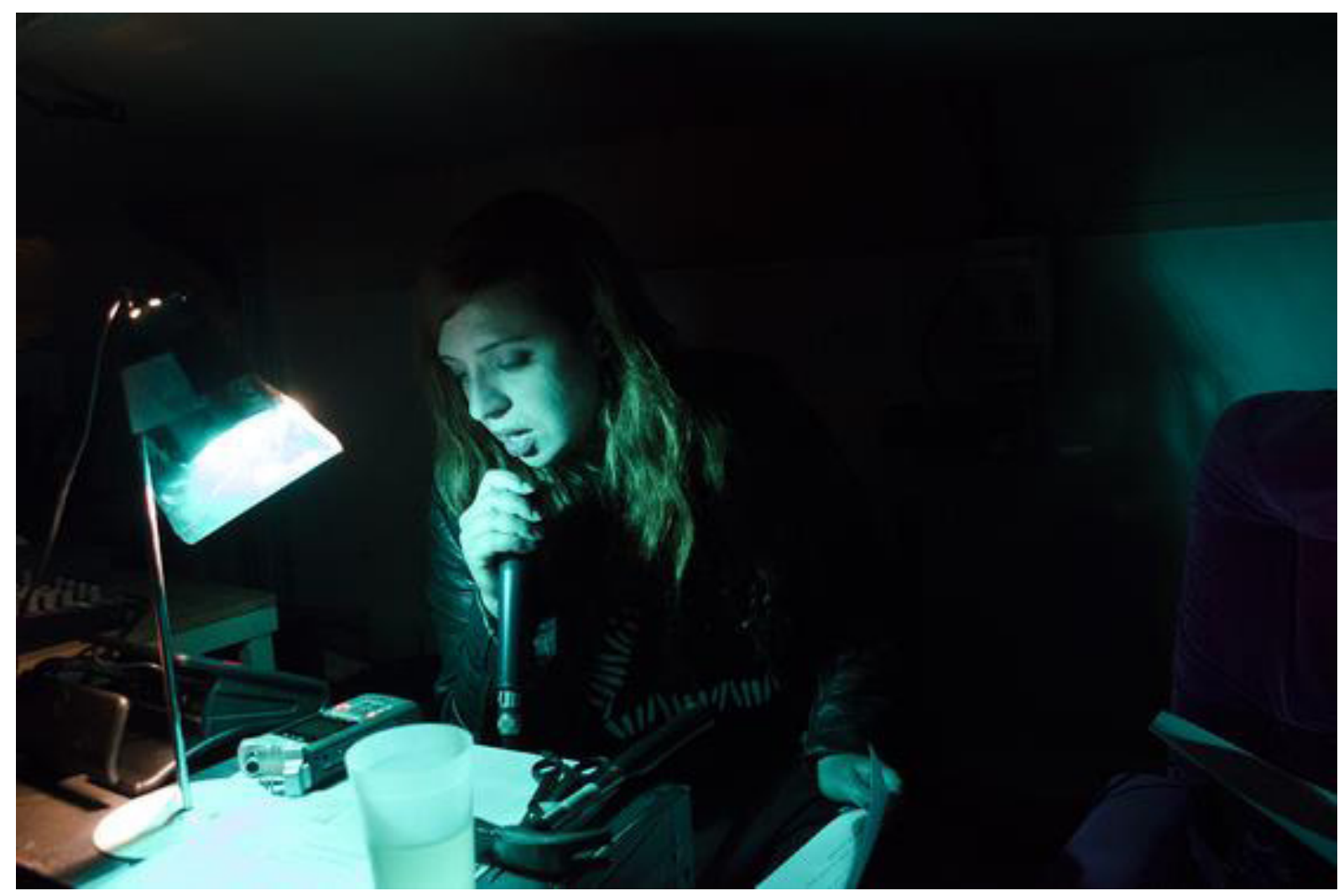

Figura 13. Documentação de performance Cut-up Tragedy na abertura da exposição Déambulations Poétiques realizada na CP5/Le Shakirail/Curry-Vavart. Foto de Isabel da Cunha, Paris, 2015. 




Figura 14. Documentação da exposição Braises d'Aujourd'hui, realizada no Confluences, Paris, 2015.

A partir dessas imagens, textos e sons, a proposta é realizar séries de livros-discos, assim como desdobramentos em espaços públicos e privados. Um desses desdobramentos previstos é o de produzir cartazes lambe-lambe e deslocar imagens e escritas vistas nos muros de uma cidade para várias outras. Esta tática de deslocamento por diferentes espaços através dos cartazes também pode ser aplicada a imagens de outros trabalhos, como Um Fardo de Palavras, em que trechos poéticos escritos em pedras portuguesas de Copacabana podem, talvez, vir a estampar muros, tetos e calçadas de Lisboa.

Cut-up Tragedy lida com deslocamentos em espaços públicos e com a ideia de uma linguagem que possa perturbar, como as ondas sonoras são uma perturbação. Busca a linguagem como um corte, uma abertura, um vírus, uma arma para transformar o que nos destrói em algo que nos vivifique. Em um plano mais abstrato, é como diz Didier Girard sobre a obra de Burroughs: "A escrita se faz então na justaposição aleatória de palavras para usar, abusar e esgotar o poder de manipulação da linguagem, quando ela se civiliza e se faz 'funcional'" (Girard apud Ferraz; Baron, 2012, p. 160). Ou, dito de uma maneira mais corporal, por Bell Hooks, em "Yearning": 
Atrevo-me a falar em uma língua que vai além dos limites da dominação - uma língua que não vai prender você, cercear, segurar. [...] Nossas palavras são uma ação, uma resistência. A linguagem também é um lugar de luta. [...] Para mim esse espaço de abertura radical é uma margem, borda que se aprofunda. Localizar-se ali é difícil. Não é um lugar seguro. Se está sempre em risco. É preciso uma comunidade de resistência. (Hooks, Loc. 2643)

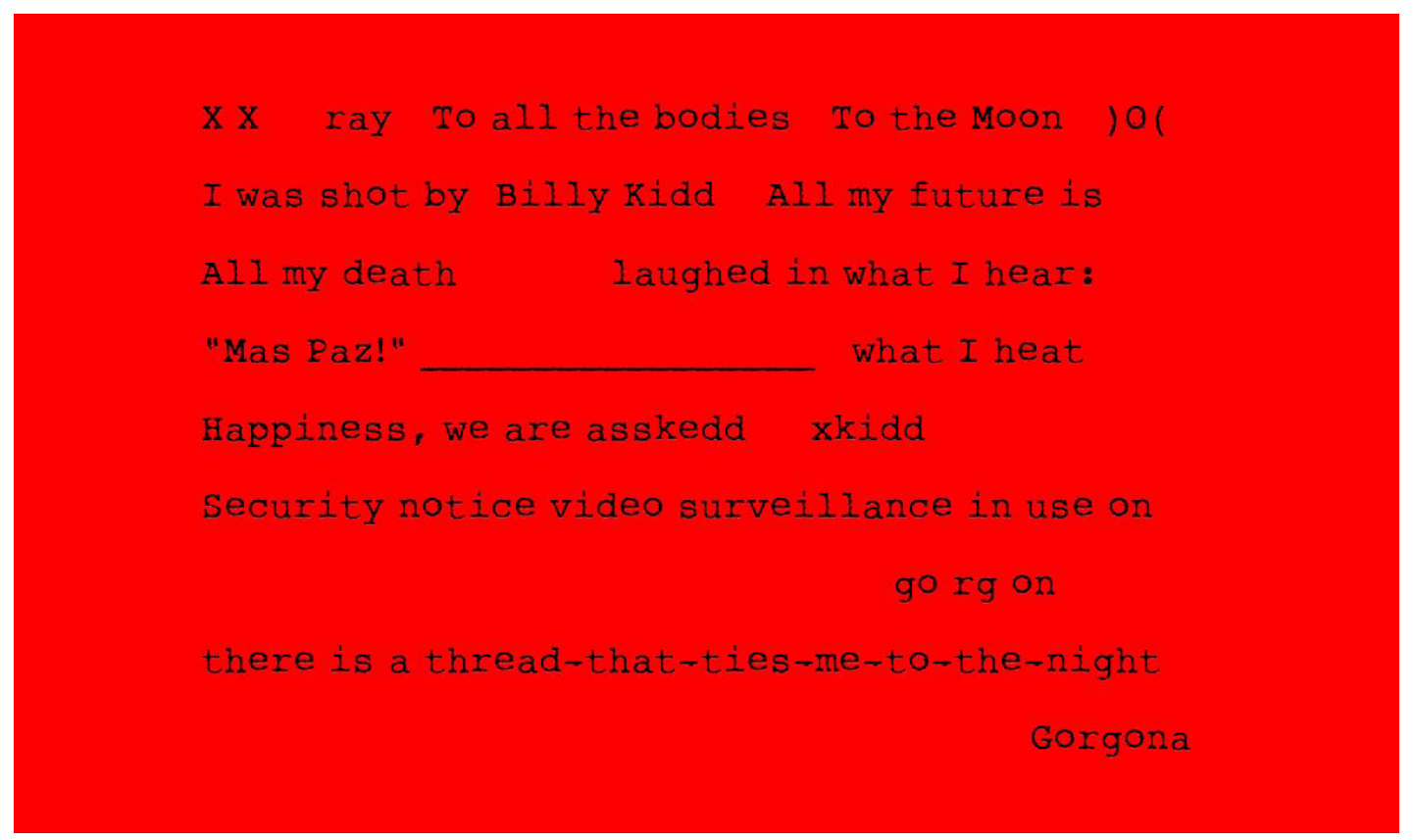

Figura 15. Adesivo da série-projeto Cut-up Tragedy, 2015

\section{Referências}

ABRAM, David. The spell of the sensuous. New York: Vintage, 1997.

ALŸS, Francis. A Story of Deception. Catálogo de exposição itinerante. Editado por M. Godfrey e K. Biesenbach. London/New York: Tate/MoMa, [20--].

ANDERSON, Laurie. I in U / Eu em Tu. Catálogo da exposição realizada em 2010 no CCBB-SP e em 2011 no CCBB-RJ. Santana do Parnaíba, SP: Mag Mais Rede Cultural, 2011.

. In: GOLDBERG, RoseLee. Laurie Anderson. London: Thames \& Hudson, 2000.

. Stories from the Nerve Bible. New York: Harper Perennial, 1993. 
ATTALI, Jacques. Noise and Politics. In: COX, C.; WARNER, D. (Eds.). Audio Culture: Readings in Modern Music. New York: Continuum, 2004.

AUGÉ, Marc. Não-Lugares: Introdução a uma Antropologia da Supermodernidade. Campinas, SP: Papirus, 1997.

AUGOYARD, Jean-François; TORGUE, Henry (Eds.). Sonic Experience: A Guide for Everyday Sounds. Montreal: McGill-Queen's University Press, 2008.

BAGATOLI, Vera Maria. Caminhar como poética. In: ENCONTRO DA ANPAP, 18., 2009, Salvador. Anais... Salvador: EDUFBA, 2009. p. 2755-2766.

BARTHES, Roland. A câmera clara. Notas sobre a fotografia. Rio de Janeiro: Nova Fronteira, 1984.

BAUdELAIRE, Charles. Poesia e Prosa. Rio de Janeiro: Nova Aguilar, 1995

BENJAMIN, Walter. Passagens. São Paulo/Belo Horizonte: Imprensa Oficial do Estado/Ed.UFMG, 2006.

. Haxixe. São Paulo: Brasiliense, 1984.

. Sur le pouvoir d'imitation. Oeuvres. Paris: Gallimard, 2000.

. Obras Escolhidas: Magia e técnica, arte e política. V. 1. São Paulo: Brasiliense, 2012.

. Obras Escolhidas: Rua de mão única. V. 2. São Paulo: Brasiliense, 2012.

BHABHA, H. Locais da Cultura. In: O Local da Cultura. Belo Horizonte: Ed. UFMG, 1998.

BORGES, Jorge Luis. Obras Completas. V. 1. São Paulo: Editora Globo, 1998.

BRECHT, Bertold. Manual para os Citadinos. Poemas. São Paulo: Editora 34, 2000.

BUFFET, Laurent (Org.). Itinérances: L'Art em Déplacement. [Paris]: De L'Incidence Ed., 2012. 
. L'Art em Déplacement. In: BUFFET, Laurent (Org.). Itinérances: L'Art em Déplacement. [Paris]: De L'Incidence Ed., 2012. p. 7-16.

BULL, Michael. Auditory. In: JONES, Caroline A. (Ed.). Sensorium: embodied experience, technology, and contemporary art. Cambridge: MIT, 2006.

BULL, Michael; BACK, Les (Eds.). The Auditory Culture Reader. Oxford/New York: Berg, 2003.

BURROUGHS, W.; GYSIN, B. The Third Mind. New York: The Viking Press, 1978.

CAESAR, Rodolfo. O Tímpano é Uma Tela!. Catálogo da exposição Arte e Música. Rio de Janeiro: Metrópolis Produções Culturais \& Caixa Cultural, 2008.

CAGE, John. Silence: Lectures and Writings by John Cage. Middletown: Wesleyan University Press. Textos de 1939 a 1958. 1. ed., 1961. Reed. 1973.

CARDIFF, J. Interview with Kelly Gordon. 2005. Avaible from: <http://hirshhorn. si.edu/exhibitions/description. asp?Type=past\&ID $=20>$.

CLASSEN, Constance. The Witch's Senses: Sensory Ideologies and Transgressive Femininities from Renaissance to Modernism. In: HOWES, David (Ed.). Empire of the Senses: The Sensual Culture Reader. Oxford, New York: Berg, 2005.

CLIFFORD, J. Sobre a alegoria etnográfica. In: A Experiência Etnográfica: antropologia e literatura no séc. XX. Rio de Janeiro: Ed. UFRJ, 2002. p. 63-99.

COX, Christoph; WARNER, Daniel (Eds.). Audio Culture: Readings in Modern Music. New York: Continuum, 2004.

COWEN, Elise. O indizível nos cadernos de Elise Cowen. Revista Contemporartes, 2014. Disponível em: <http://www.revistacontemporartes.com.br/2014/12/o-indizivel-nos-cadernos-de-elise-cowen.html>.

CRITON, Pascale. O Ouvido Ubíquo: Escutar de outro modo. Cadernos de Subjetividade, São Paulo, PUC - Núcleo de Estudos e Pesquisas da Subjetividade, ano 9, n. 14, 2012. 
DAVILA, Thierry et al. Les Figures de La Marche. Catálogo de exposição realizada no Musée Picasso, Antibes. 2000.

. Errare Humanum Est. In: Les Figures de La Marche. Catálogo de exposição realizada no Musée Picasso, Antibes. 2000. p. 253-313.

- Marcher, Créer. Déplacements, flâneries, dérives dans l'art de la fin du XXe siécle. Paris: Regard, 2002.

DEBORD, Guy. Teoría de La Deriva. [S.I.: s.n., 1958].

. Methods of Détournement. Les Lèvres Nues, n. 8, 1956. Disponível em: $<$ http://library.nothingness.org/articles/SI/en/display/3>.

. Theory of the Dérive. Internationale Situationniste, n. 2, 1958. Disponível em: <http://library.nothingness.org/articles/SI/en/display/314>.

DELEUZE, Gilles; GUATTARI, Félix. Mil Platôs: Capitalismo e Esquizofrenia. V.3. São Paulo: Editora 34, 1996.

. Mil Platôs: Capitalismo e Esquizofrenia. V. 4. São Paulo: Editora 34, 1997. . O que é a Filosofia?. São Paulo: Editora 34, 1997.

DIDI-HUBERMAN, Georges. Sortir du Gris. In : La Traversée. Texto no catálogo da exposição de Mathieu Pernot realizada no Museu Jeu De Paume. Paris: Le Point du Jour, 2014.

Pensar Debruçado. Lisboa: KKYM, 2015.

DRIFT/DÉRIVE. Ramifications d'une notion polysémique. Catálogo/ publicação coletiva. Genéve: HEAD; Dijon: Les Presses du Réel, 2014.

DYSON, Frances. Sounding new media: immersion and embodiment in the arts and culture. Berkeley: UC Press, 2009.

FELD, Steven. Places Sensed, Senses Placed: Toward a Sensuous Epistemology of 
Enviroments. In: HOWES, David (Ed.). Empire of the senses: the sensual culture reader. Oxford; New York: Berg, 2005.

FERRAZ, M.C.F.; BARON, L. Potências e Práticas do Acaso: o acaso na filosofia, na cultura e nas artes ocidentais. Rio de Janeiro: FAPERJ/Garamond, 2012.

FLUSSER, Vilém. Texto/imagem enquanto dinâmica do ocidente. Cadernos RioArte, Rio de Janeiro, Caderno lilás, v. 2, n. 5, p. 64-68, jan. 1986.

FULTON, Hamish. Walking Transformation. Catálogo de exposição. Köln: Vila Merkel/Snoeck, 2014

GAGNEBIN, J.M. História e narração em Walter Benjamin. São Paulo: Perspectiva, 1999.

. Lembrar escrever esquecer. São Paulo: Ed. 34, 2006.

Apagar os rastros, recolher os restos. In: SELDMAYER, S.; GINZBURG J. (Orgs.). Walter Benjamin: Rastro, Aura e História. Belo Horizonte: UFMG, 2012.

GERALDO, Sheila Cabo. Vizinhança incomum. Concinnitas - Revista do Instituto de Artes da UERJ, Rio de Janeiro, ano 12, v. 1, n. 18, p. 80-81, jun. 2011.

GIBSON, James J. The ecological approach to visual perception. New York: Taylor \& Francis Group, 1986.

GINZBURG, Jaime. A interpretação do rastro em Walter Benjamin. In: SELDMAYER, S.; GINZBURG J. (Orgs.). Walter Benjamin: Rastro, Aura e História. Belo Horizonte: UFMG, 2012.

GIRARD, Didier. Ghost of Chance: Interzonas de Risco de William Burroughs. In: FERRAZ, M.C.F.; BARON, L. Potências e Práticas do Acaso: o acaso na filosofia, na cultura e nas artes ocidentais. Rio de Janeiro: FAPERJ; Garamond, 2012.

GOODMAN, Steve. Sonic warfare: sound, affect and the ecology of fear. Cambridge: The MIT Press, 2010. 
GUATTARI, Félix. As três ecologias. Campinas: Papirus, 1990.

HARAWAY, Donna. Staying with the trouble: Making kin in the Chthulucene. London: Duke University, 2016.

HOHMANN, K.; TIÈCHE, A. Commencer pour ne pas finir/ Starting in order not to finish. In : DRIFT/DÉRIVE. Ramifications d'une notion polysémique. Catálogo/publicação coletiva. Genéve: HEAD; Dijon: Les Presses du Réel, 2014.

HOOKS, Bell. Yearning: Race, gender and cultural politics. New York: Routledge, 2015.

HOWES, David (Ed.). Empire of The Senses: The Sensual Culture Reader. Oxford; New York: Berg, 2005.

. Introduction. In: (Ed.). Empire of the senses: the sensual culture reader. Oxford; New York: Berg, 2005.

Hyperesthesia, or, The Sensual Logic of Late Capitalism. In: (Ed.). Empire of the senses: the sensual culture reader. Oxford; New York: Berg, 2005. IHDE, Don. Auditory Imagination. Originalmente publicado In: . Listening and Voice - A Phenomenology of Sound, 1976. Republicado In: BULL, Michael; LES BACK (Eds.). The Auditory Culture Reader, Oxford/New York: Berg, 2003.

IVERSEN, M. (Org.). Chance. London/Cambridge: Whitechapell + The MIT Press, 2010.

IYER, Vijay. On improvistion, temporality and embodied experience. In: MILLER, Paul D. (Ed.). Sound unbound: sampling digital music and culture. Cambridge: The MIT Press, 2008.

JACKSON, J.B. Discovering The Vernacular Landscape. New Haven/London: Yale University Press, 1984.

. J.B. A Sense of Place, A Sense of Time. New Haven/London: Yale University Press, 1994. 
JANZ, Rolf-Peter. Ausente e Presente: Sobre o Paradoxo da aura e do vestígio. In: SELDMAYER, S.; GINZBURG J. (Orgs.). Walter Benjamin: Rastro, Aura e História. Belo Horizonte: UFMG, 2012. p. 11-26.

JOHNSON, Ronna C.; GRACE, Nancy M. Girls Who Wore Black: Women Writing the Beat Generation. New Jersey: Rutgers University Press, 2002.

JONES, Caroline A. Sensorium: embodied experience, technology, and contemporary art. Cambridge: MIT, 2006.

KAHN, Douglas. Noise, water, meat: a history of sounds. Cambridge: The MIT Press, 1999.

KELLY, Caleb (Ed.). Sound - Documents of Contemporary Art. London/Cambridge: Whitechapel/MIT, 2011

KIM-COHEN, Seth. In the blink of an ear: toward a non-cochlear sonic art. New York: Continuum, 2010.

KRAUSS, Rosalind. O fotográfico. Barcelona: Ed. Gustavo Gili, AS, 2002.

KWON, Miwon. O lugar errado. Revista Urbania, São Paulo, n. 3, abr. 2008.

. One place after another: site specific art and locational identity. Cambridge: MIT Press, 2004.

LABELLE, Brandon. Background Noise: Perspectives in Sound Art. New York: Continuum, 2010a.

Acoustic territories: sound culture and everyday life. New York: Continuum, 2010b.

LATOUR, Bruno. Face à Gaïa. Paris: La Découverte, 2015.

LEÃO, Lucia. A Estética do Labirinto. São Paulo: Anhembi Morumbi, 2002.

LÉVINAS, Emmanuel. O humanismo do outro homem. Petrópolis: Vozes, 2012. 
LONG, Richard. Selected Statements and Interviews. London: Haunch of Venison, 2007.

LÖWY, M., Walter Benjamin: aviso de incêndio - uma leitura das teses "Sobre o conceito de história". São Paulo: Boitempo, 2012.

MACIEL, Maria. E. A memória das coisas: ensaios de cinema, literatura e artes plásticas. Rio de Janeiro: Lamparina, 2004.

. As ironias da ordem: coleções, inventários e enciclopédias ficcionais. Belo Horizonte: UFMG, 2010.

MARX, Karl. Manuscritos econômico-filosóficos. São Paulo: Boitempo, 2004.

MASSUMI, Brian. Parables for the virtual: movement, affect, sensation. Durham; London: Duke University, 2002.

MCLUHAN, Marshall. Inside the Five Sense Sensorium. In: HOWES, David. Empire of the senses: the sensual culture reader. New York: Berg, 2005.

MILLER, Paul D. (Ed.). Sound unbound: sampling digital music and culture. Cambridge: The MIT Press, 2008.

MOTHERWELL, Robert (Ed.). The Dada Painters and Poets: An Anthology. 2. ed. Belknap/Harvard: Cambridge/London, 1981.

MUNROE, Alexandra; HENDRICKS, Jon et al. Yes Yoko Ono. New York: Japan Society/Abrams, 2000.

NESHAT, S.; MILANI, F. Shirin Neshat. Milano: Charta, 2001.

NIETZSCHE, Friedrich. Assim falou Zaratustra. Rio de Janeiro: Civilização Brasileira, 1983.

. Aurora. São Paulo: Escala, 2007.

. A Gaia Ciência. São Paulo: Cia. das Letras/Schwarcz, 2001. 
OBICI, Giuliano. Condições da escuta: mídias e territórios sonoros. Rio de Janeiro: 7Letras, 2008.

OITICICA, Hélio. Aparecimento do Suprasensorial. In: OITICICA, Hélio et al. Hélio Oiticica. Rotterdam: Witte de With; Paris: Gal. Nat. du Jeu de Paume; Rio de Janeiro: Projeto HO, 1996.

. Museu é o Mundo. Catálogo da exposição realizada em quatro cidades. Org. César OITICICA Filho. Rio de Janeiro: Beco do Azougue, 2011.

OLIVEROS, Pauline. Some Sound Observations. In: COX, C.; WARNER, D. (Eds.). Audio culture: readings in modern music. New York: Continuum, 2004.

. Deep listening: a composer's sound practice. Lincoln: iUniverse, 2005.

ONFRAY, Michel. Teoria da viagem: poética da geografia. Porto Alegre: L\&PM, 2009.

ONO, Yoko. Grapefruit. 1. ed. Tokyo: Wunternaum Press, 1964. 2. ed. New York: Simon \& Shuster, 1970. Reprints: 1992, 1998, 2000.

PELBART, Peter P. A Arte de Viver nas Linhas. In: DERDYK, Edith (Org.). Disegno. Desenho. Desígnio. São Paulo: SENAC, 2007.

. O Tempo Não Reconciliado. São Paulo: Perspectiva, 2010.

PERNOT, Mathieu. La Traversée. Texto de Georges Didi-Huberman. Catálogo de exposição realizada no Museu Jeu De Paume. Paris: Le Point du Jour, 2014.

RAINER, Cosima et al. (Orgs.). See this sound: promises in sound and vision: catálogo da exposição. Colônia: Lentos Kunstmuseum Linz, 2009.

RANCIÈRE, Jacques. A partilha do sensível: estética e política. São Paulo: Editora $34,2005$.

. A partilha do sensível: estética e política. 2. ed. São Paulo: EXO Experimental; Editora 34, 2009.

. O Espectador Emancipado. São Paulo: Martins Fontes, 2012. 
RIMBAUD, Arthur. Carta do Vidente (1871). In: LIMA, Carlos (Org.). Rimbaud no Brasil. Rio de Janeiro: UERJ/Comunicarte, 1993.

RIMBAUD, A.; BARROSO, I. Cartas do Vidente (1871). In: Correspondência. Rio de Janeiro: Topbooks, 2008.

SCHAFER, Murray. Open Ears. In: BULL, Michael; BACK, Les (Eds.). The auditory culture reader. New York: Berg, 2003.

. A afinação do mundo. São Paulo: UNESP, 1997.

SELDMAYER, S.; GINZBURG, J. (Orgs.). Walter Benjamin: Rastro, Aura e História. Belo Horizonte: UFMG, 2012.

SENNET, R. Mutual: The history, rituals, pleasures and politics of cooperation. In: Together: The history, rituals, pleasures and politics of cooperation. New Haven: Yale University Press, 2012.

SERRES, Michel. Os cinco sentidos: filosofia dos corpos misturados. Rio de Janeiro: Bertrand Brasil, 2001.

SOLNIT, Rebecca. Wanderlust: A History of Walking. Londres: Penguin Books, 2000.

SPEER, Olivia. Les marches de Francis Alÿs: une approche poétique, sociologique et critique de la ville. In : BUFFET, Laurent (Org.). Itinérances: L'Art em Déplacement. [Paris]: De L'Incidence Ed., 2012.

STENGERS, Isabelle. No Tempo das Catástrofes. São Paulo: 2015.

STEWART, Susan. Remembering the senses. In: HOWES, David (Ed.). Empire of the senses: the sensual culture reader. New York: Berg, 2005.

TIBERGHIEN, Gilles A. Bill Viola: na natureza das coisas. Concinnitas, Rio de Janeiro, ano 11, v. 2, n. 17, dez. 2010.

. Nature, art, paysage. Arles: Actes Sud/ENSP, 2001. 
. Finis Terrae: imaginaires et imaginations cartografiques. Paris: Bayard, 2007.

. Hodológico. Valise, Porto Alegre, v. 2, n. 3, ano 3, jul. 2012.

. La Marche: Emergence et fin de I'oeuvre. In : Les Figures de La Marche. Catálogo de exposição realizada no Musée Picasso, Antibes, 2000. p. 253-313.

TOOP, David. Sinister resonance: the mediumship of the listener. New York: Continuum, 2010.

TZARA, Tristan. Vingt-Cinq Poémes. Zurique-Dada, 1918.

. Como fazer um poema dadaísta. Tradução encontrada on-line.

VIOLA, Bill. Survey of a decade. Houston: Contemporary Art Museum, 1988.

. Reasons for knocking at an empty house. Cambridge: The MIT Press, 1995.

WESTERKEMP, Hildegard. Soundwalking. Originalmente publicado em Sound Heritage, Victoria B.C., v. 3, n. 4, 1974. Revisado em 2001. Publicado em: Autumn Leaves, Sound and the Environment in Artistic Practice, Ed. Angus Carlyle, Double Entendre, Paris, p. 49, 2007.

WILLER, Cláudio. A Geração Beat. Porto Alegre: L\&PM, 2009.

\section{Links sobre mulheres beatniks:}

http://www.beatdom.com/women-of-the-beat-generation/

http://forbookssake.net/2014/11/19/top-5-women-writers-beat-generation/

http://the-artifice.com/beat-generation-women/ 